\title{
Exploring quercetin and luteolin derivatives as antiangiogenic agents
}

Article

Accepted Version

Ravishankar, D., Watson, K. A., Boateng, S. Y., Green, R. J., Greco, F. and Osborn, H. M.I. (2015) Exploring quercetin and luteolin derivatives as antiangiogenic agents. European Journal of Medicinal Chemistry, 97. pp. 259-274. ISSN 02235234 doi: https://doi.org/10.1016/j.ejmech.2015.04.056 Available at https://centaur.reading.ac.uk/40222/

It is advisable to refer to the publisher's version if you intend to cite from the work. See Guidance on citing.

To link to this article DOI: http://dx.doi.org/10.1016/j.ejmech.2015.04.056

Publisher: Elsevier

All outputs in CentAUR are protected by Intellectual Property Rights law, including copyright law. Copyright and IPR is retained by the creators or other copyright holders. Terms and conditions for use of this material are defined in the End User Agreement.

\section{www.reading.ac.uk/centaur}

\section{CentAUR}

Central Archive at the University of Reading 
Reading's research outputs online 


\section{Exploring quercetin and luteolin derivatives as antiangiogenic agents}

Divyashree Ravishankar $^{\mathrm{a}}$, Kimberly A. Watson ${ }^{\mathrm{b}}$, Samuel Y. Boateng ${ }^{\mathrm{b}}$, Rebecca J. Green ${ }^{\mathrm{a}}$, Francesca Greco ${ }^{\text {a* }}$, Helen. M. I. Osborn ${ }^{\mathrm{a} *}$.

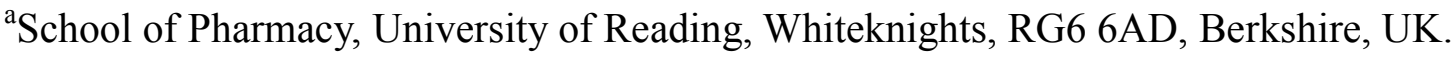

${ }^{\mathrm{b}}$ Institute of Cardiovascular and Metabolic Research, School of Biological Sciences, University of Reading, Whiteknights, RG6 6AD, Berkshire, UK.

\section{GRAPHICAL ABSTRACT}

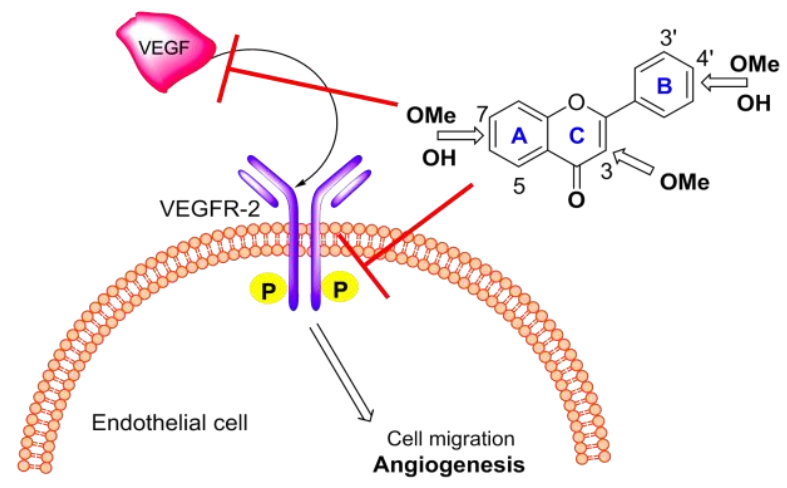

\section{HIGHLIGHTS}

- Synthesis of methoxy and 4-thio derivatives of quercetin and luteolin is reported.

- The majority of these compounds exhibited potential antiangiogenic activity.

- The active compounds displayed high binding affinities with VEGF and VEGFR2.

- Structure-activity relationships are defined.

- Antiproliferative activity and membrane perturbation effects are presented.

ABSTRACT: The formation of new blood vessels from the pre-existing vasculature (angiogenesis) is a crucial stage in cancer progression and, indeed, angiogenesis inhibitors are now used as anticancer agents, clinically. Here we have explored the potential of flavonoid derivatives as antiangiogenic agents. Specifically, we have synthesised methoxy and 4-thio derivatives of the natural flavones quercetin and luteolin, two of which (4-thio quercetin and 4thio luteolin) had never been previously reported. Seven of these compounds showed significant 
$(\mathrm{P}<0.05)$ antiangiogenic activity in an in vitro scratch assay. Their activity ranged from an $86 \%$ inhibition of the vascular endothelium growth factor (VEGF)-stimulated migration (observed for methoxyquercetin at $10 \mu \mathrm{M}$ and for luteolin at $1 \mu \mathrm{M}$ ) to a $36 \%$ inhibition (for thiomethoxy quercetin at $10 \mu \mathrm{M}$ ). Western blotting studies showed that most (4 out of 7) compounds inhibited phosphorylation of the VEGF receptor-2 (VEGFR2), suggesting that the antiangiogenic activity was due to an interference with the VEGF/VEGFR2 pathway. Molecular modelling studies looking at the affinity of our compounds towards VEGFR and/or VEGF confirmed this hypothesis, and indeed the compound with the highest antiangiogenic activity (methoxyquercetin) showed the highest affinity towards VEGFR and VEGF. As reports from others have suggested that structurally similar compounds can elicit biological responses via a non-specific, promiscuous membrane perturbation, potential interactions of the active compounds with a model lipid bilayer were assessed via DSC. Luteolin and its derivatives did not perturb the model membrane even at concentrations 10 times higher than the biologically active concentration and only subtle interactions were observed for quercetin and its derivatives. Finally, cytotoxicity assessment of these flavonoid derivatives against MCF-7 breast cancer cells demonstrated also a direct anticancer activity albeit at generally higher concentrations than those required for an antiangiogenic effect (10 fold higher for the methoxy analogues). Taken together these results show promise for flavonoid derivatives as antiangiogenic agents.

KEYWORDS: Angiogenesis, flavones, quercetin, luteolin, antiangiogenic therapy

\section{INTRODUCTION}

Angiogenesis is a physiological process involving the formation of new blood vessels from preexisting blood vessels. It is a complex process characterized by the proliferation, migration, sprouting and elongation of endothelial cells [1], and plays an important role during cell reproduction and organ development, as well as in wound healing processes. Under pathological 
conditions, angiogenesis is poorly regulated and contributes to the pathogenesis of various diseases such as rheumatoid arthritis, inflammation, psoriasis, degenerative eye conditions and, of particular relevance to our study, cancer [2]. Sustained angiogenesis is one of the central hallmarks of cancer $[3,4]$ and has been validated as a key target for cancer therapy [5], as evidenced by several antiangiogenic agents having entered clinical practice in the last decade (for example, bevacizumab (Avastin ${ }^{\circledR}$ for several metastatic cancers) and sunitinib maleate (SU11248, Sutent ${ }^{\circledR}$ for renal cell carcinoma and gastrointestinal stromal tumour)).

Flavonoids are polyphenolic compounds that have attracted ongoing and recent interest due to their potential anticancer properties. They are very well known for their antiproliferative activities against various cell lines [6] with some flavonoids such as flavopiridol [7-9], silibinin (also known as silybin) [10], quercetin [11] and its derivative QC12 [12] having progressed to various stages of clinical trials. Interestingly, recent studies have highlighted that two common dietary flavonoids (quercetin and luteolin) inhibit angiogenesis in vitro and in vivo $[13,14]$ at concentrations $10-40 \mu \mathrm{M}$. Also, other structurally similar flavones have been reported to possess antiangiogenic properties. In order to develop and optimise the flavone scaffolds into a pharmaceutical agent, a better understanding of the structure-activity relationships (SARs) is crucial. Hence, in this study, the antiangiogenic properties of a panel of small molecules, comprised of quercetin and luteolin, as well as their rationally designed and synthesised derivatives, are probed to allow a better understanding of the structure activity relationships of flavonoids as antiangiogenic agents.

Many antiangiogenic agents exhibit their action by interfering with the vascular endothelial growth factor (VEGF) and the VEGF receptor-2 (VEGFR2) [15]. Therefore, the compounds reported in our study were evaluated for their potential to inhibit the VEGF-stimulated effects in an in vitro model comprised of endothelial cells. The molecular mechanism of action of these 
derivatives was investigated using Western blotting and additionally in silico studies were conducted to probe the interactions of this panel of molecules with VEGFR2 and VEGF. Additionally, we probed the interactions of these synthesised compounds with a model lipid bilayer in order to determine the possible contribution of a membrane perturbation effect towards the observed biological activity. Finally, as flavonoid derivatives are known to display direct anticancer activity against tumour cells, cytotoxicity studies against a breast cancer cell line (MCF-7) and a chemotherapy resistant sub-strain (MCF-7/DX) were also carried out. This cytotoxicity assessment was carried out to investigate how variations in the chemical structure of the flavonoid derivatives affected their activity, but also to establish the concentrations required to elicit direct anticancer activity compared to those required for antiangiogenic effects. Indeed, a widely reported problem associated with antiangiogenic drugs that target endothelial proliferation is their inhibition of the proliferation of other cell types, which leads to undesirable cell toxicity; molecules with high selectivity towards VEGF/VEGFR2 with low cytotoxicity are considered to be ideal candidates for antiangiogenic therapy as well as for combination therapy [16].

\section{RESULTS AND DISCUSSION}

This paper reports the synthesis of methoxy and 4-thio derivatives of quercetin and luteolin, which includes two new derivatives (4 and 12) and explores how subtle variations in the chemical structure of flavonoids affect their biological activity, particularly in relation to their antiangiogenic activity.

\subsection{Synthesis}

In order to gain a better understanding of SARs, a rational panel of compounds (2-4 and 9-12) comprised of flavonoids with differing numbers of hydroxyl groups (quercetin versus luteolin), different lipophilicities (hydroxyl versus methylated derivatives), and different key functional 
groups (4-C=O versus 4-C=S) (Figure-1) was synthesised in good yields (ranging from $20 \%$ to $30 \%$ overall yield). The derivatives of quercetin (2-4) and luteolin (9-12) were prepared using the general synthetic approaches outlined in Scheme-1 and 2 respectively.

Synthesis of quercetin derivatives: The polymethylated derivative of quercetin, namely methoxyquercetin (2) was obtained by the methylation of quercetin (1) using dimethyl sulfate in the presence of $15 \% \mathrm{KOH}$, in $60 \%$ yield. The compound methoxyquercetin (2) was treated with Lawesson's reagent in anhydrous toluene to obtain the 4-thio derivative, thiomethoxyquercetin (3) in $65 \%$ yield. The thiomethoxyquercetin (3) was demethylated using $\mathrm{BBr}_{3}$ in anhydrous dichloromethane at $40{ }^{\circ} \mathrm{C}$ for $18 \mathrm{~h}$ to afford thioquercetin (4) in $55 \%$ yield (Scheme-1).

Synthesis of luteolin derivatives: The first step in the synthesis of luteolin (10) and its derivatives was esterification of 2-hydroxy-4,6-dimethoxyacetophenone (5) with 3,4-dimethoxy benzoyl chloride (6) in pyridine and this was achieved in $60 \%$ yield. The obtained ester (7) was converted to a 1,3-diketone (8) via a Baker-Venkataramann rearrangement in the presence of $\mathrm{KOH}$ in pyridine in approximately $75 \%$ yield. This 1,3-diketone (8) underwent cyclodehydration in the presence of an acid to give the methoxyluteolin (9) in $70 \%$ yield. The hydroxy flavone, luteolin (10), was obtained by demethylation of methoxyluteolin using $\mathrm{BBr}_{3}$ in anhydrous dichloromethane at $40{ }^{\circ} \mathrm{C}$ for $18 \mathrm{~h}$ in $59 \%$ yield. The 4-thiomethoxy derivative of luteolin (11) was obtained in $61 \%$ yield by treating the methoxyluteolin (9) with Lawesson's reagent. Thioluteolin (12) was successfully synthesised by the demethylation of thiomethoxyluteolin (11) using $\mathrm{BBr}_{3}$ in anhydrous dichloromethane at $40{ }^{\circ} \mathrm{C}$ for $18 \mathrm{~h}$ in $55 \%$ yield (Scheme-2). The identities of these synthesised compounds were confirmed by ${ }^{1} \mathrm{H}$ NMR, ${ }^{13} \mathrm{C}$ NMR and IR spectroscopy, and mass spectrometry. Also, the purity of these compounds were determined to be $>95 \%$ pure by HPLC. 


\section{Scheme 1- Synthesis of methoxy and 4-thiocarbonyl analogues of quercetin}

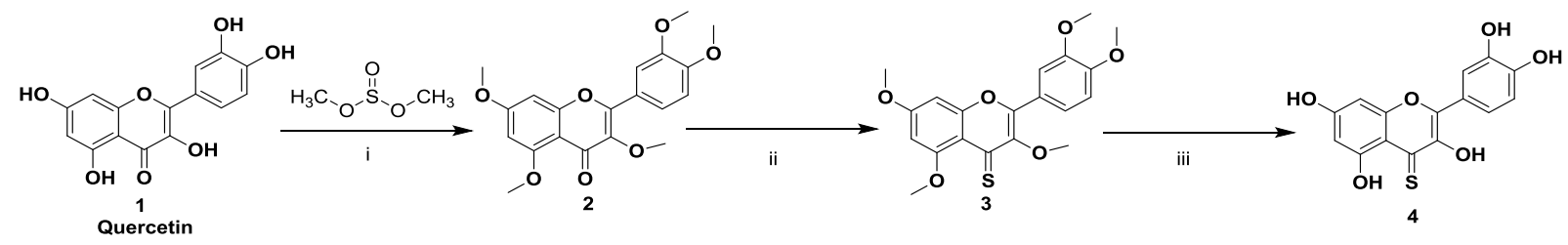

(i) $15 \% \mathrm{KOH}$, room temperature to $90{ }^{\circ} \mathrm{C}$, overnight; (ii) Dry toluene, Lawesson's reagent, $110{ }^{\circ} \mathrm{C}, 4 \mathrm{~h}$; (iii) Dry DCM, $\mathrm{BBr}_{3}, 40{ }^{\circ} \mathrm{C}$, overnight.

\section{Scheme 2- Synthesis of luteolin and its methoxy and 4-thiocarbonyl analogues}

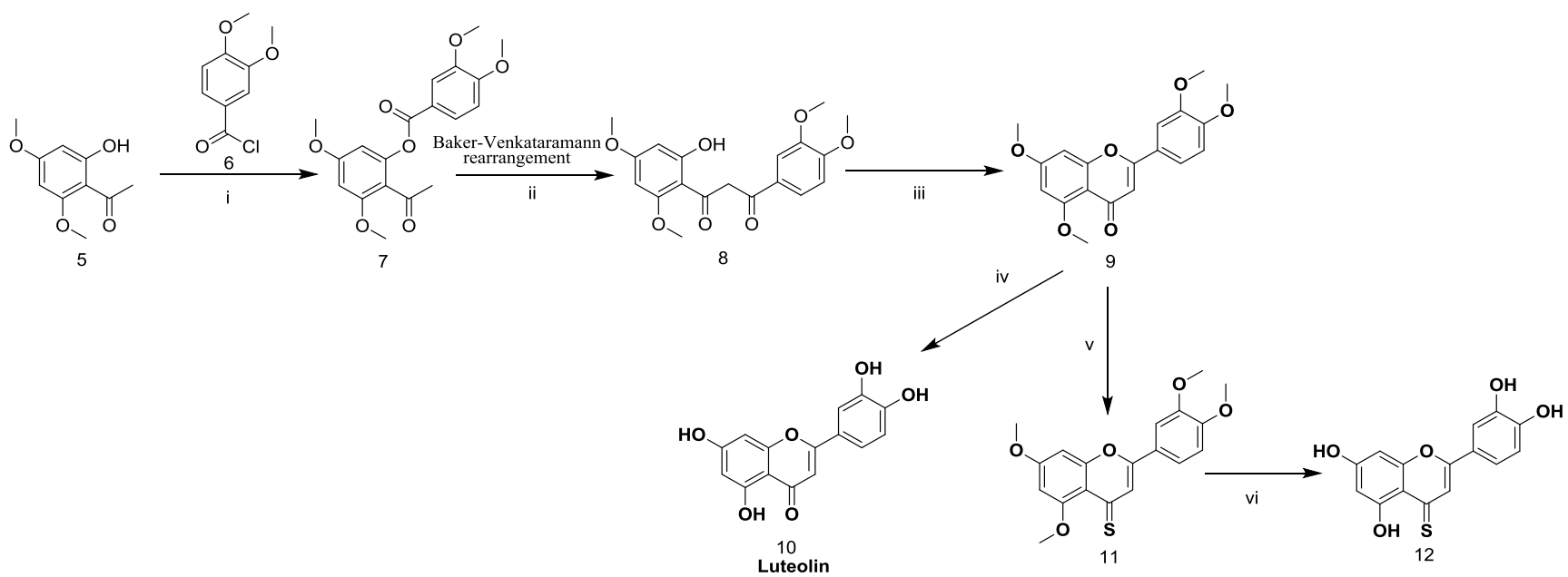

(i) Pyridine, $75{ }^{\circ} \mathrm{C}, 1 \mathrm{~h}$; (ii) Pyridine, $\mathrm{KOH}, 50-75{ }^{\circ} \mathrm{C}, 2 \mathrm{~h}$; (iii) Glacial acetic acid, $1 \% \mathrm{H}_{2} \mathrm{SO}_{4}, 90-110{ }^{\circ} \mathrm{C}, 1 \mathrm{~h}$,

(iv) Dry DCM, $\mathrm{BBr}_{3}, 40{ }^{\circ} \mathrm{C}$, overnight; (v) Dry toluene, Lawesson's reagent, $110{ }^{\circ} \mathrm{C}$, 4 h; (vi) Dry $\mathrm{DCM} \mathrm{BBr}_{3}$, $40{ }^{\circ} \mathrm{C}$, overnight.

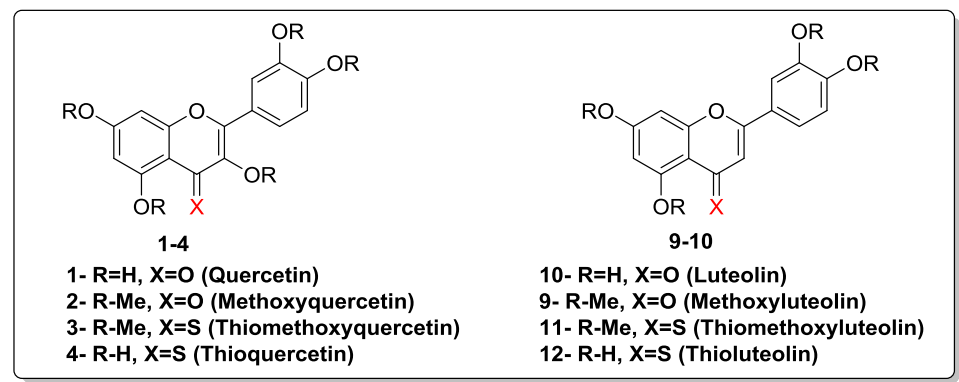

Figure 1. The quercetin and luteolin derivatives synthesised and evaluated in this study. 


\subsection{Antiangiogenic studies}

\subsubsection{Scratch assay}

Following the synthesis of the quercetin and luteolin derivatives (2-4 and 9-12, respectively), their antiangiogenic properties were assessed in vitro. The antiangiogenic potencies of these compounds were assessed at the cellular level using human umbilical endothelial vascular cells (HUVECs) using a well-established in vitro model $[17,18]$. The migration of endothelial cell is a key step in the process of angiogenesis [19]. HUVECs show very high rates of migration when stimulated with the chemokine VEGF. Therefore, the antiangiogenic potencies of these derivatives were assessed through their ability to inhibit the VEGF-induced migration of HUVECs using an in vitro scratch/wound healing assay [20].

The effects of quercetin, luteolin and their derivatives on the inhibition of the chemotactic motility of HUVECs are shown in Figures-2 and 3. All compounds were initially screened at 10 $\mu \mathrm{M}$ concentration. However, changes in the cell morphology were observed in the presence of luteolin (Figure-3) as well as the 4-thio derivatives of quercetin (4) and luteolin (12) (data not shown) at this concentration, which indicates an undesirable level of toxicity. Hence, compounds 10, 4 and 12, along with quercetin (for comparison), were tested at a lower $(1 \mu \mathrm{M})$ concentration. Figure-2 shows the effects of quercetin and its derivatives on VEGF-induced cell migration. Quercetin at $10 \mu \mathrm{M}$ exhibited $74 \%$ inhibition of VEGF-induced cell migration, and this is in agreement with previous reports [13]. Also, when tested at $1 \mu \mathrm{M}$ concentration, quercetin still retained antiangiogenic properties with $54 \%$ inhibition of VEGF-stimulated migration. The newly synthesised 4-thio derivative of quercetin (4) displayed 47\% inhibitory effect at $1 \mu \mathrm{M}$ concentration, which is comparable to that of quercetin at the same concentration. Interestingly, the methoxy derivative of quercetin (2) at $10 \mu \mathrm{M}$ concentration showed $86 \%$ inhibition of VEGF-stimulated migration whereas its 4-thio analogue (3) at $10 \mu \mathrm{M}$ concentration 
displayed $63 \%$ inhibition. Among quercetin and its derivatives, the inhibitory effect observed is in the order of compound-2 $\geq$ compound-1>compound-3>compound-4. Figure-3 shows the profile for luteolin and its derivatives. Luteolin at $10 \mu \mathrm{M}$ displayed undesirable morphological changes, however such observation has not been reported in the previous study [14]. At $1 \mu \mathrm{M}$ concentration, luteolin exhibited $86 \%$ inhibition of VEGF-stimulated migration. The new 4-thio derivative of luteolin (12) showed statistically significant inhibition of VEGF-stimulated migration at $1 \mu \mathrm{M}$. The methoxy derivative of luteolin (9) and its 4-thio analogue (11) at their $10 \mu \mathrm{M}$ concentration exhibited $58 \%$ and $36 \%$ inhibition of VEGF-stimulated migration respectively. Among luteolin and its derivatives, the inhibitory effect observed is in the order of compound-10>compound-9>compound-11>compound-12.
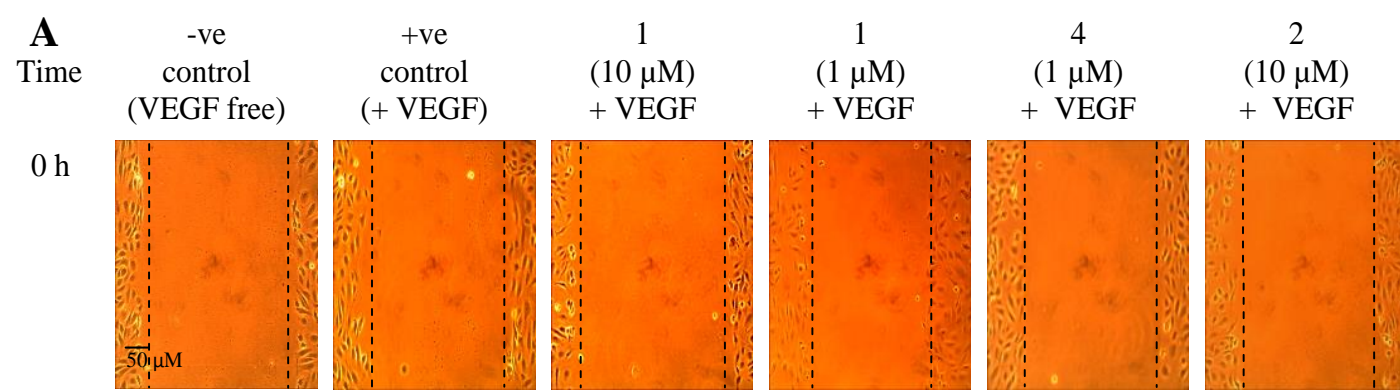

3
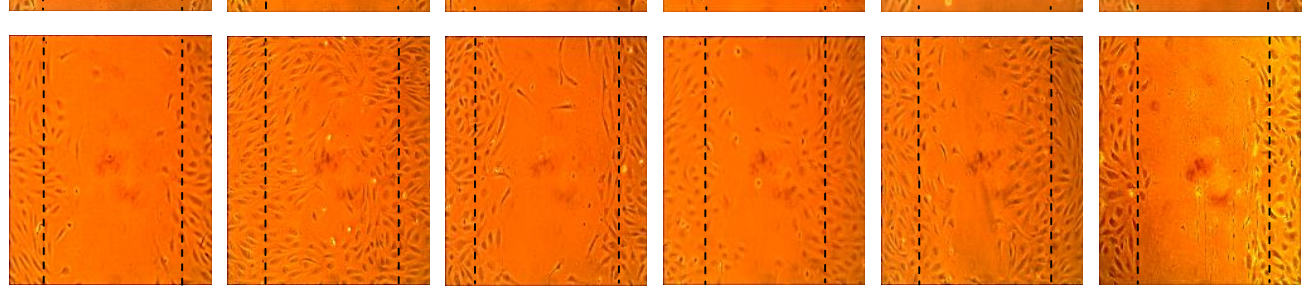


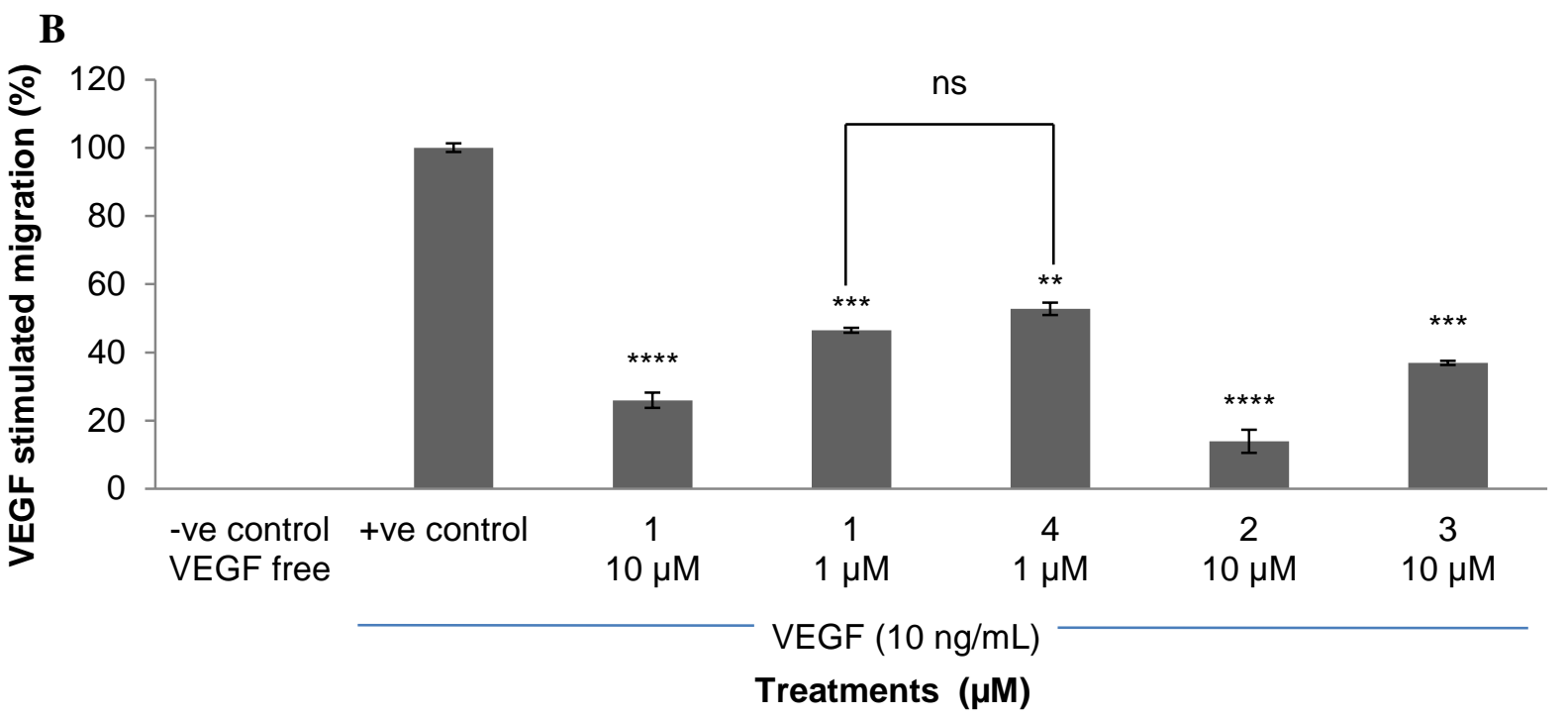

Figure 2. Effects of quercetin and its derivatives on VEGF-mediated cell migration in an in vitro scratch assay. ARepresentative images of scratch assay of HUVEC with the treatments, -ve control- without VEGF, +ve controlwith VEGF (10 ng/mL), quercetin (1) $[10 \mu \mathrm{M}+10 \mathrm{ng} / \mathrm{mL}$ VEGF], quercetin (1) $[1 \mu \mathrm{M}+10 \mathrm{ng} / \mathrm{mL} \mathrm{VEGF}]$, thioquercetin (4) $[1 \mu \mathrm{M}+10 \mathrm{ng} / \mathrm{mL}$ VEGF $]$, methoxyquercetin (2) $[10 \mu \mathrm{M}+10 \mathrm{ng} / \mathrm{mL}$ VEGF $]$, thiomethoxyquercetin $(3)[10 \mu \mathrm{M}+10 \mathrm{ng} / \mathrm{mL}$ VEGF]. The images were acquired at 10X magnification, size bar 50 $\mu \mathrm{M}$. Dashed lines represent the margins of the initial scratch, area covered by HUVEC after $12 \mathrm{~h}$ was quatified using ImageJ software. B- Bar chart represent the quantification of the inhibitory effect of quercetin and its derivatives on VEGF stimulated migration, expressed as percentage of the scratched area covered by HUVEC after $12 \mathrm{~h}$ migration and normalized to presence/absence of VEGF (100\% and 0\% for VEGF and VEGF-free medium, respectively). The results for compound-4 at $10 \mu \mathrm{M}$ is not reported as signs of toxicity were observed for that compound at $10 \mu \mathrm{M}$ concentration. Data are expressed as mean \pm standard error of the mean $(\mathrm{SEM}), \mathrm{n}=3$. Statistical significance was estimated with respect to the +ve control by one-way ANOVA, followed by Bonferroni's post hoc test (ns = nonsignificant; $\left.{ }^{*}, \mathrm{p}<0.05, * *, \mathrm{p}<0.01, * * *, \mathrm{p}<0.001, * * * *, \mathrm{p}<0.0001\right)$ 
A
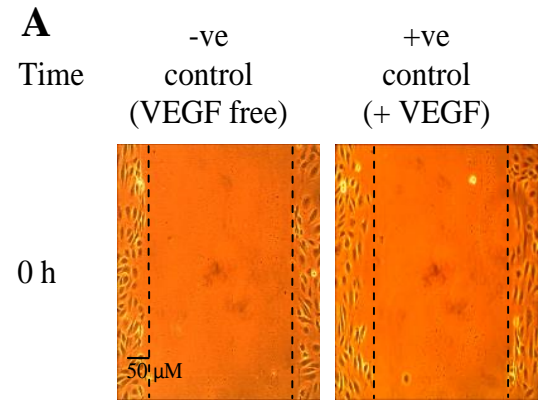

10

$(10 \mu \mathrm{M})$

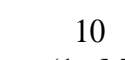

10
$(1 \mu \mathrm{M})$

+ VEGF

+ VEGF
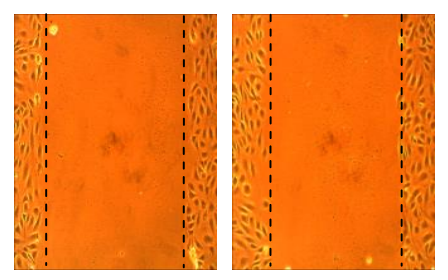

$(1 \mu \mathrm{M})$

+ VEGF

9

11

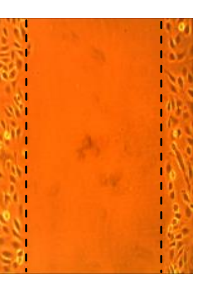

$(10 \mu \mathrm{M})$
$+\mathrm{VEGF}$

$(10 \mu \mathrm{M})$

, VEGF

+ VEGF

$12 \mathrm{~h}$
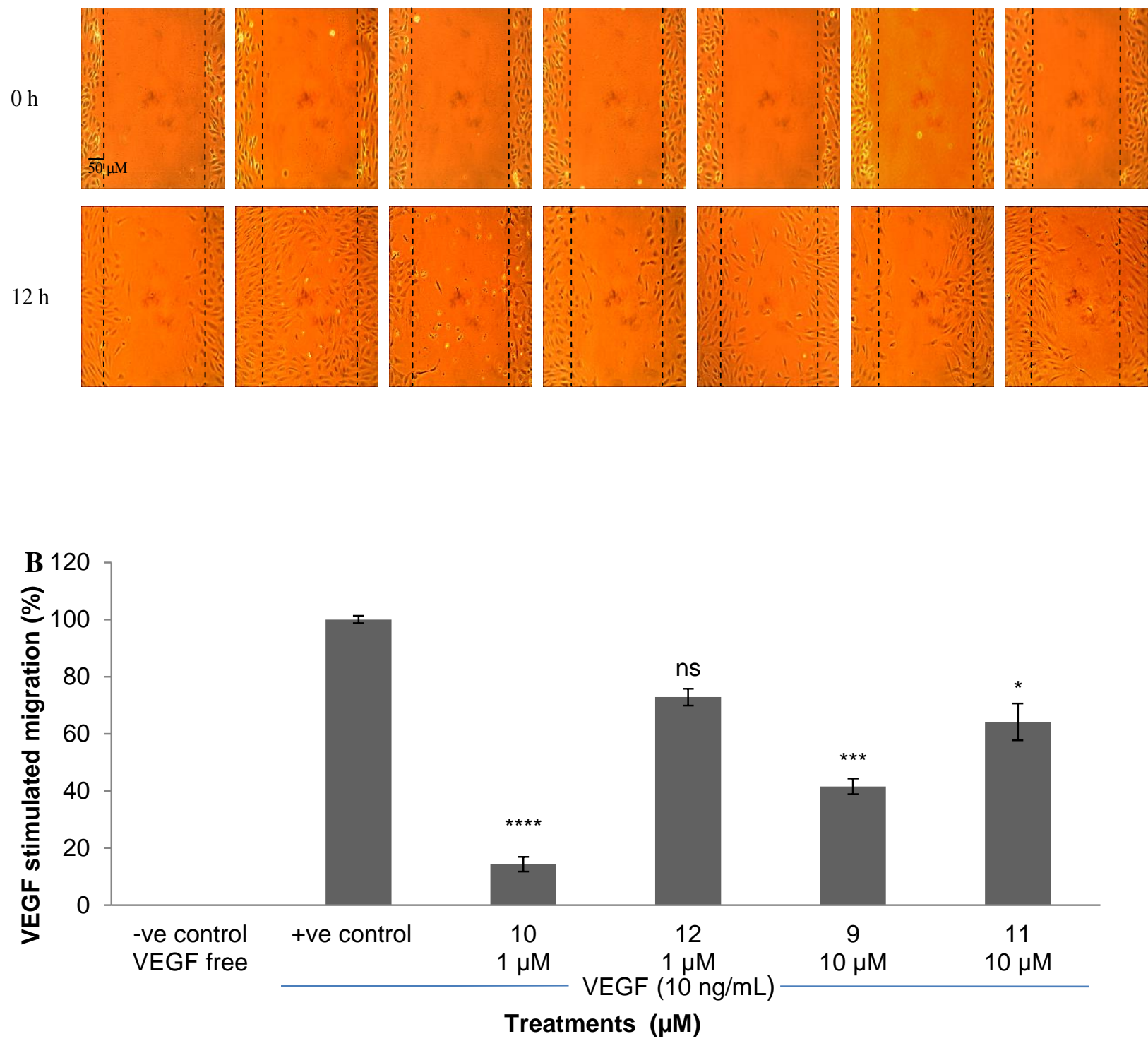

Figure 3. Effects of luteolin and its derivatives on VEGF-mediated cell migration in an in vitro scratch assay. ARepresentative images of scratch assay of HUVEC with the treatments, -ve control- without VEGF, +ve controlwith VEGF (10 ng/mL), luteolin (10) $[1 \mu \mathrm{M}+10 \mathrm{ng} / \mathrm{mL}$ VEGF], thioluteolin (12) $[1 \mu \mathrm{M}+10 \mathrm{ng} / \mathrm{mL} \mathrm{VEGF}]$, methoxyluteolin (9) $[10 \mu \mathrm{M}+10 \mathrm{ng} / \mathrm{mL}$ VEGF], thiomethoxyluteolin (11) $[10 \mu \mathrm{M}+10 \mathrm{ng} / \mathrm{mL}$ VEGF $]$. The images were acquired at $10 \mathrm{X}$ magnification, size bar $50 \mu \mathrm{M}$. Dashed lines represent the margins of the initial scratch, area covered by HUVEC after $12 \mathrm{~h}$ was quatified using ImageJ software. B-Bar chart represent the quantification of the inhibitory effect of luteolin and its derivatives on VEGF stimulated migration, expressed as percentage of the scratched area covered by HUVEC after $12 \mathrm{~h}$ migration and normalized to presence/absence of VEGF (100\% and 0\% for VEGF and VEGF-free medium, respectively). The results for compounds-10 and 12 at 10 
$\mu \mathrm{M}$ are not reported as signs of toxicity were observed for those compounds at $10 \mu \mathrm{M}$ concentration. Data are expressed as the mean \pm standard error of the mean $(\mathrm{SEM}), \mathrm{n}=3$. Statistical significance was estimated with respect to the +ve control by one-way ANOVA, followed by Bonferroni's post hoc test (ns = nonsignificant; *, p < $0.05, * * *, \mathrm{p}<0.001, * * * *, \mathrm{p}<0.0001)$.

\subsubsection{Western blotting}

Having observed the inhibition of VEGF induced cell migration in the presence of quercetin and the luteolin derivatives, their possible mechanisms of angiogenesis inhibition were elucidated using Western blotting. VEGF signalling via the phosphorylation of VEGFR2 promotes cell growth and survival [21]. Tyr1175 is a major phosphorylation site of VEGFR2 and its phosphorylation triggers a downstream signalling cascade, which ultimately results in increased endothelial cell proliferation, migration and vascular permeability [22]. Thus, quercetin, luteolin and their derivatives that showed significant inhibition of the VEGF stimulated cell migration in the in vitro scratch assay were investigated for their effects on VEGFR2 autophosphorylation at Tyr1175 site in HUVEC's.

In general, the results obtained from the Western blotting analysis (Figure-4) mirror the results obtained with the scratch assay. VEGF $(10 \mathrm{ng} / \mathrm{mL})$ [+ve control] significantly promoted the levels of phosphorylated VEGFR2 (P-VEGFR2) in comparison to the -ve control without VEGF stimulation. In the case of quercetin and its derivatives, quercetin (1) at both $10 \mu \mathrm{M}$ and $1 \mu \mathrm{M}$, its methoxy derivative (2) and thiomethoxy derivative (3) at $10 \mu \mathrm{M}$ all showed significant reduction in the levels of P-VEGFR2, whereas, such reduction in the levels of P-VEGFR2 was not displayed by the 4-thio derivative of quercetin (4) at $10 \mu \mathrm{M}$ concentration. As mentioned earlier, the order of inhibitory effect correlated well with the scratch assay results, i.e. compound-2 $\geq$ compound-1 $>$ compound-3>compound-4. In the case of luteolin and its derivatives only luteolin at $1 \mu \mathrm{M}$ concentration displayed significant reduction in the P-VEGFR2 levels while its methoxy and 4-thiomethoxy derivatives (9 and 11) did not show significant inhibition 
on the VEGF-induced autophosphorylation of VEGFR2. These results suggest that compounds1, 2, 3 and $\mathbf{1 0}$ mediates their antiangiogenic effects via the suppression of VEGFR2 phosphorylation.

VEGF (10 ng/mL)

A

Quercetin and its derivatives Luteolin and its derivatives

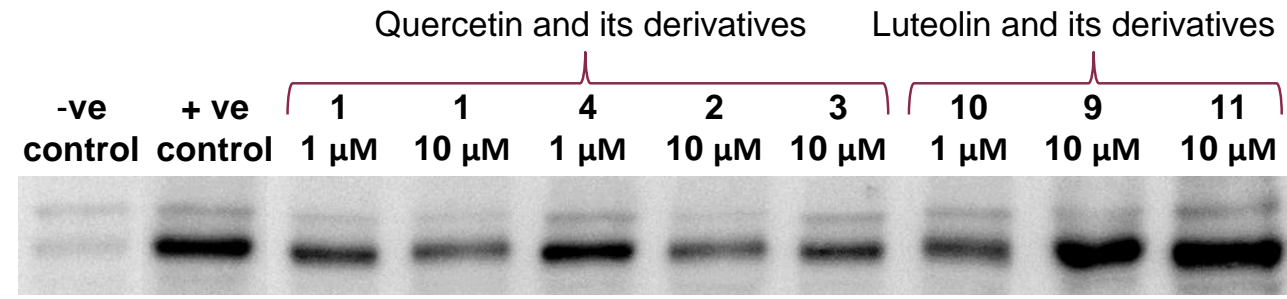

P-Actin

P-VEGFR2

(Tyr1175)

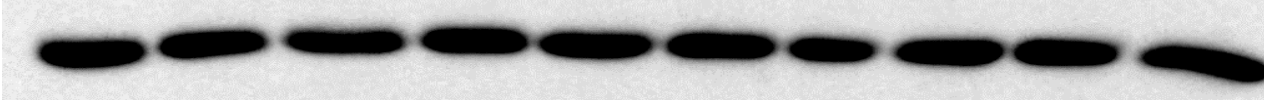

T-VEGFR2

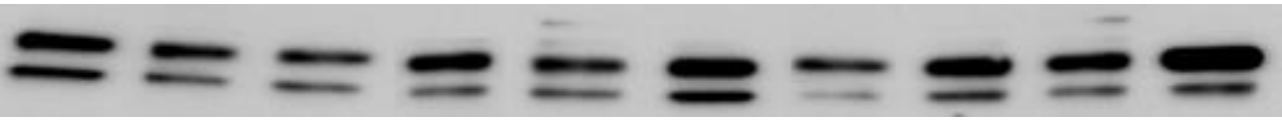

T-Actin
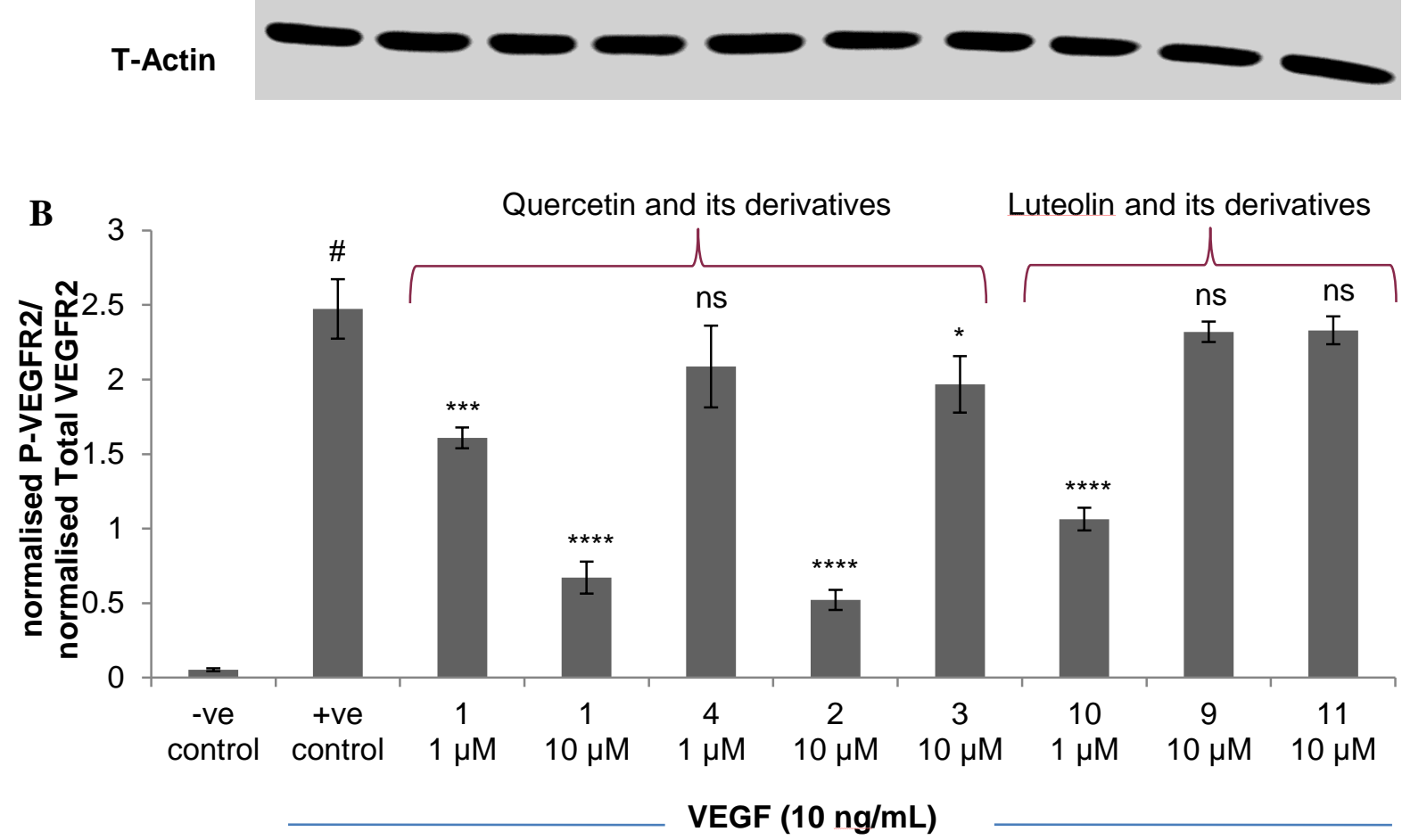

Figure 4. A-Representative Western blot images of HUVEC proteins with the treatments, -ve control- without VEGF, +ve control- with VEGF (10 ng/mL), quercetin (1) $[10 \mu \mathrm{M}+10 \mathrm{ng} / \mathrm{mL}$ VEGF], quercetin $(\mathbf{1})[1 \mu \mathrm{M}+10$ ng/mL VEGF], thioquercetin (4) $[1 \mu \mathrm{M}+10 \mathrm{ng} / \mathrm{mL}$ VEGF], methoxyquercetin (2) $[10 \mu \mathrm{M}+10 \mathrm{ng} / \mathrm{mL} \mathrm{VEGF}]$, thiomethoxyquercetin (3) $[10 \mu \mathrm{M}+10 \mathrm{ng} / \mathrm{mL}$ VEGF], luteolin (10) $[1 \mu \mathrm{M}+10 \mathrm{ng} / \mathrm{mL}$ VEGF], methoxyluteolin 
(9) $[10 \mu \mathrm{M}+10 \mathrm{ng} / \mathrm{mL}$ VEGF], thiomethoxyluteolin (11) $[10 \mu \mathrm{M}+10 \mathrm{ng} / \mathrm{mL}$ VEGF]; actin was used as a loading control. B- Bar chart represents the quantification of the inhibitory effect of quercetin, luteolin and its derivatives on VEGF induced phosphorylation. Data are expressed as mean \pm standard error of the mean $(\mathrm{SEM}), \mathrm{n}=3$. Statistical significance was estimated vs the +ve control by one-way ANOVA, followed by Bonferroni's post hoc test (\#-significant with respect to -ve control, ns = nonsignificant; $*, p<0.05, * * *, p<0.001, * * * *, p<0.0001)$.

\subsection{Molecular docking}

Molecules that interfere with the VEGF/VEGFR signalling pathway typically work by either blocking the VEGF ligand directly or by inhibiting its receptor VEGFR2. Hence, molecular docking studies were conducted to elucidate the potential molecular interactions between quercetin and luteolin derivatives and both VEGFR2 and VEGF. The derivatised molecules were docked sequentially into the respective binding sites, using the X-ray crystallographic structures of VEGFR2 receptor (PBD code-1YWN) and VEGF (PBD code-1VPP). The docking procedure was first validated by re-docking the extracted co-crystallised ligand of VEGFR2 (4amino-furo[2,3-d]pyrimidine) into the prepared protein to be used for docking. The RMSD between the docked conformation generated by the program and the native co-crystallized ligand conformation was found to be $0.10 \AA$, well within the $2 \AA$ grid spacing used for docking, indicating that the docking procedure to be used was reliable and valid. Furthermore, the interactions between the docked ligand and the receptor mimicked those observed in the crystal structure of the same.

Interactions with VEGFR2: The results of ligand-directed docking into the ATP-binding site of VEGFR2 are summarised in Table-S1 (see supporting information) in decreasing order of the ligand binding affinities, as determined by their docking scores. The binding modes of quercetin, luteolin and their derivatives with VEGFR2 are depicted in Figure-5. The quercetin and luteolin derivatives have shown potential interactions with the key residues, Glu-883, Lys- 
866 and Cys-917 of VEGFR2 through hydrogen bonding. The docking scores suggest that compounds $\mathbf{2 , 1 0}$ and $\mathbf{3}$ have greater binding affinity towards VEGFR2.

Interactions with VEGF: The results of automated docking procedure with VEGF are summarised in Table-S2 (see supporting information) in decreasing order of the ligand binding affinities, as determined by their docking scores. The binding modes of quercetin, luteolin and their derivatives with VEGF are depicted in Figure-6. The quercetin and luteolin derivatives have also shown potential interactions with the key residues, Leu-32V, Gly-59V and Asp-34W residues of VEGF through hydrogen bonding. Compounds 9, 2 and $\mathbf{1 1}$ showed greater binding affinity towards VEGF.

Among these compounds, the methoxy derivative of quercetin (compound-2) has shown higher binding affinities towards both VEGFR2 and VEGF. This compound was found binding to the ATP binding site of VEGFR2 through the formation of hydrogen bonds to the 'hinge' region

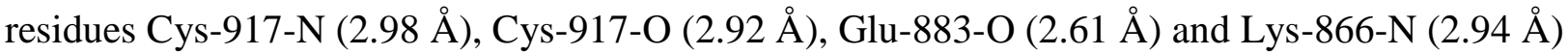
residue of the hydrophobic pocket, and also through hydrophobic interactions (Figure-5). The major interactions of compound-2 with VEGF are Leu-32V-N (2.98 ^), Gly-59V-N (2.79, 2.91 $\AA$ ), and Asp-34W-N (3.13 ̊) (Figure-6). In general, the analysis of molecular docking results revealed that compound-2 possibly acts as an inhibitor of VEGFR2 and its binding potency relies on strong hydrophobic interactions between the compound and the binding site of the receptor. Also, the docking studies suggested that the higher binding affinities of compound-2 towards both VEGFR2 and VEGF could possibly be the reason for its antiangiogenic activity as observed in both the scratch assay and Western blotting. Similarly, the weaker antiangiogenic activities of the 4-thio derivatives of quercetin and luteolin could be because of their poor binding affinities towards VEGFR2 and VEGF. This could be further verified in future studies by utilising a cell free protein kinase assay of VEGFR2. 

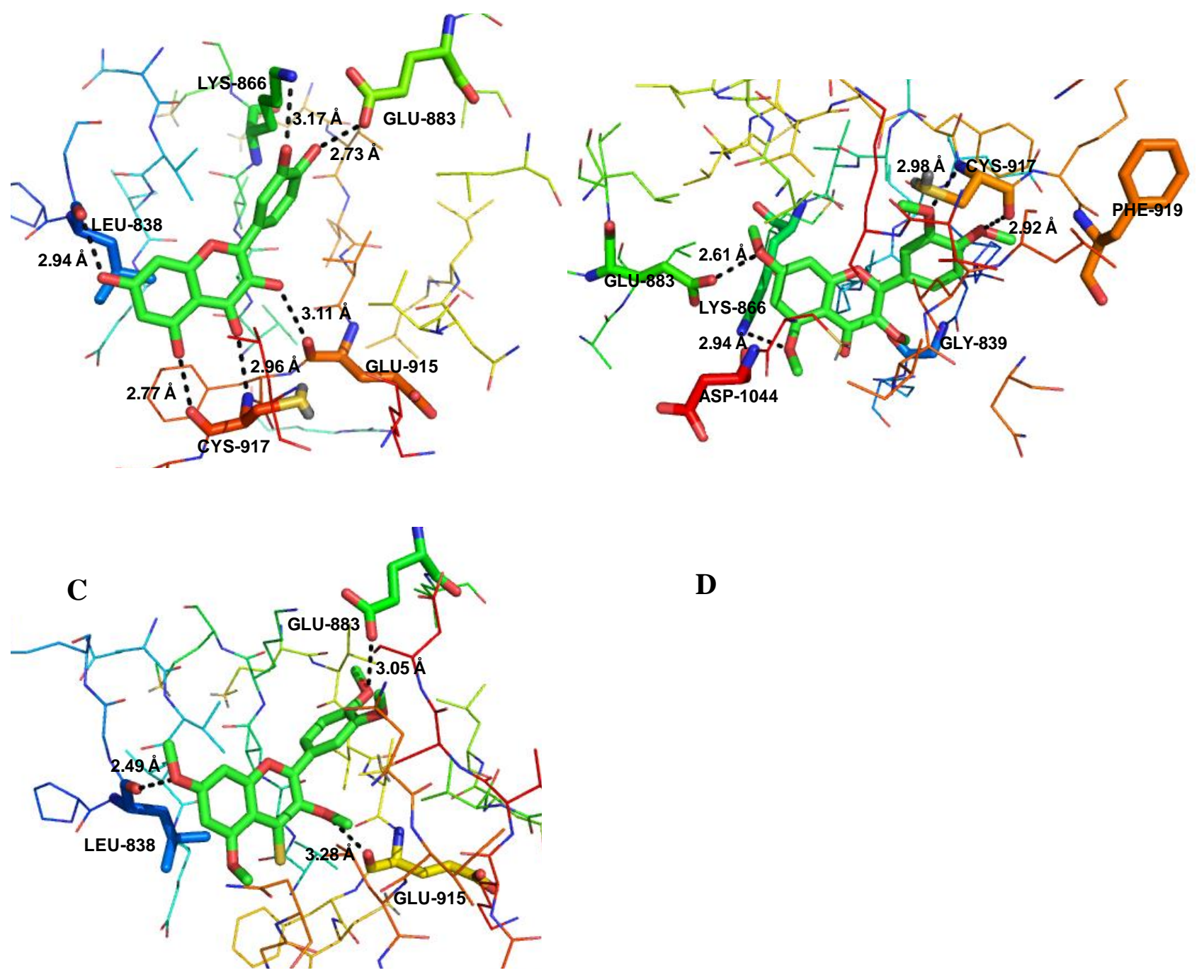

D

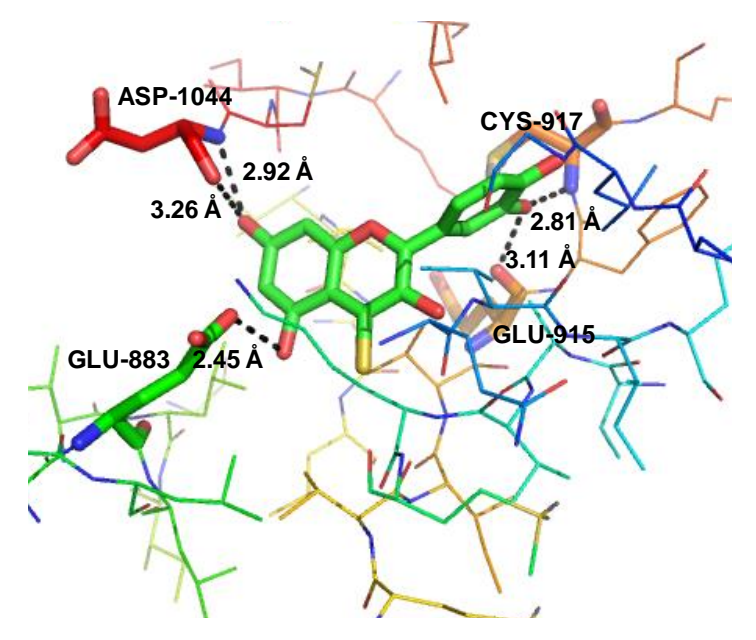



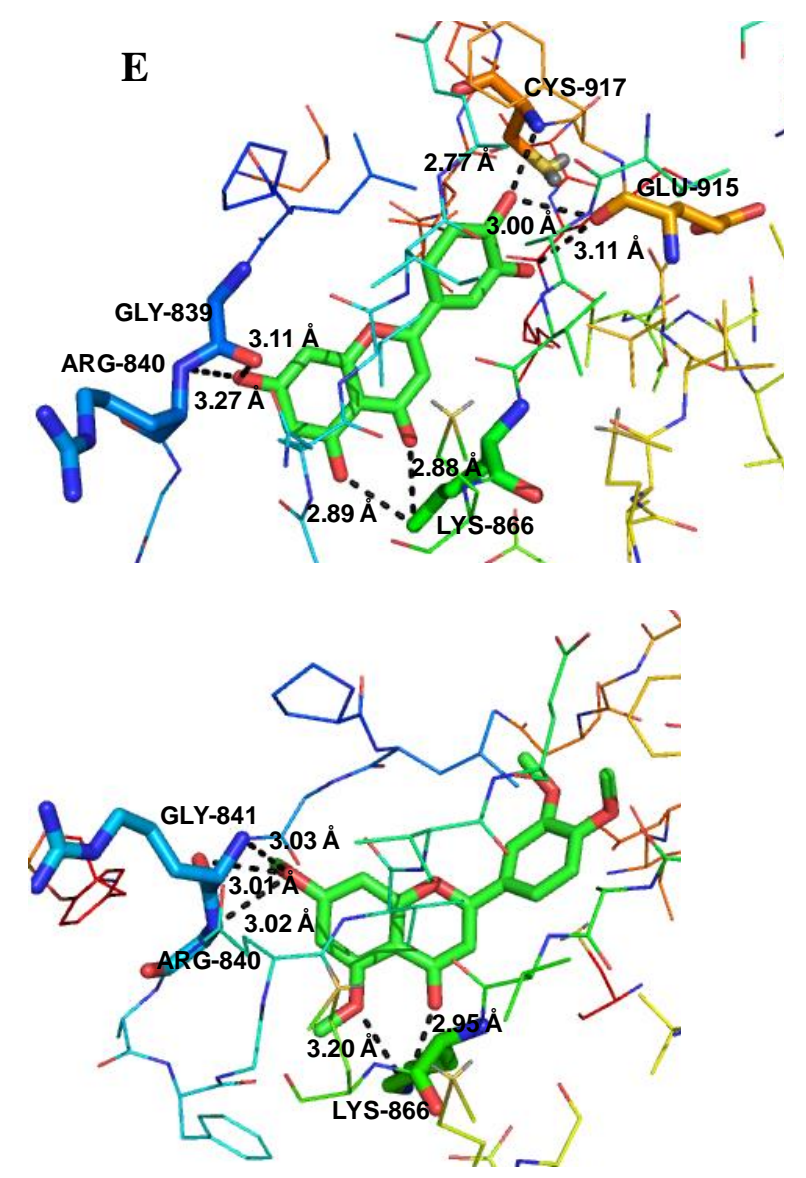


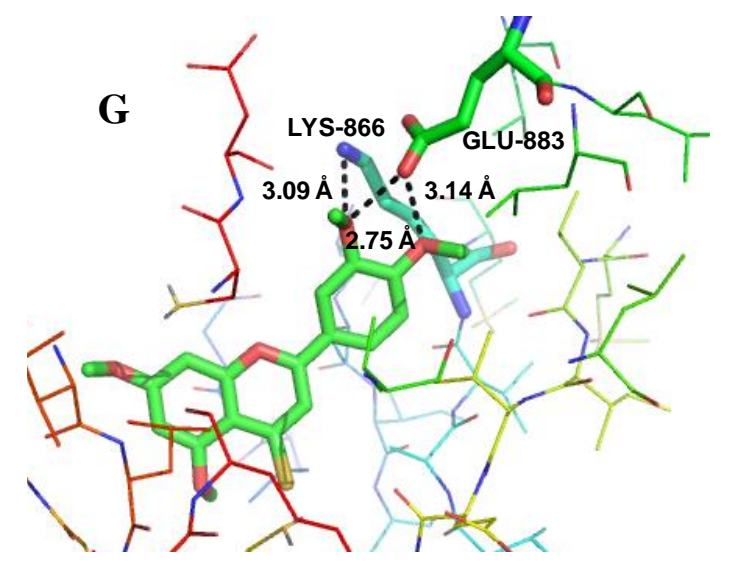

$\mathbf{H}$

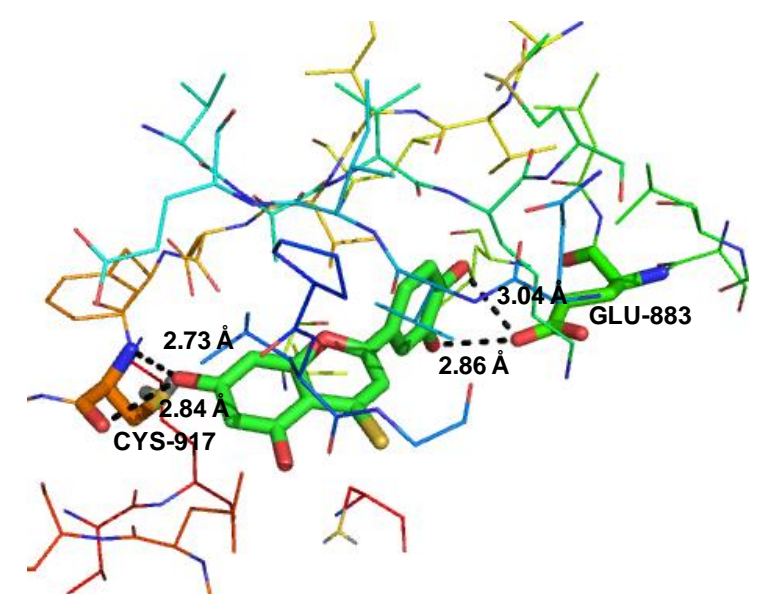

Figure 5. Docking modes of quercetin (1) (A), methoxy quercetin (2) (B), thiomethoxy quercetin (3) (C), thioquercetin (4) (D), luteolin (10) (E), methoxy luteolin (9) (F), thiomethoxy luteolin (11) (G), thioluteolin (12) (H) with VEGFR2.
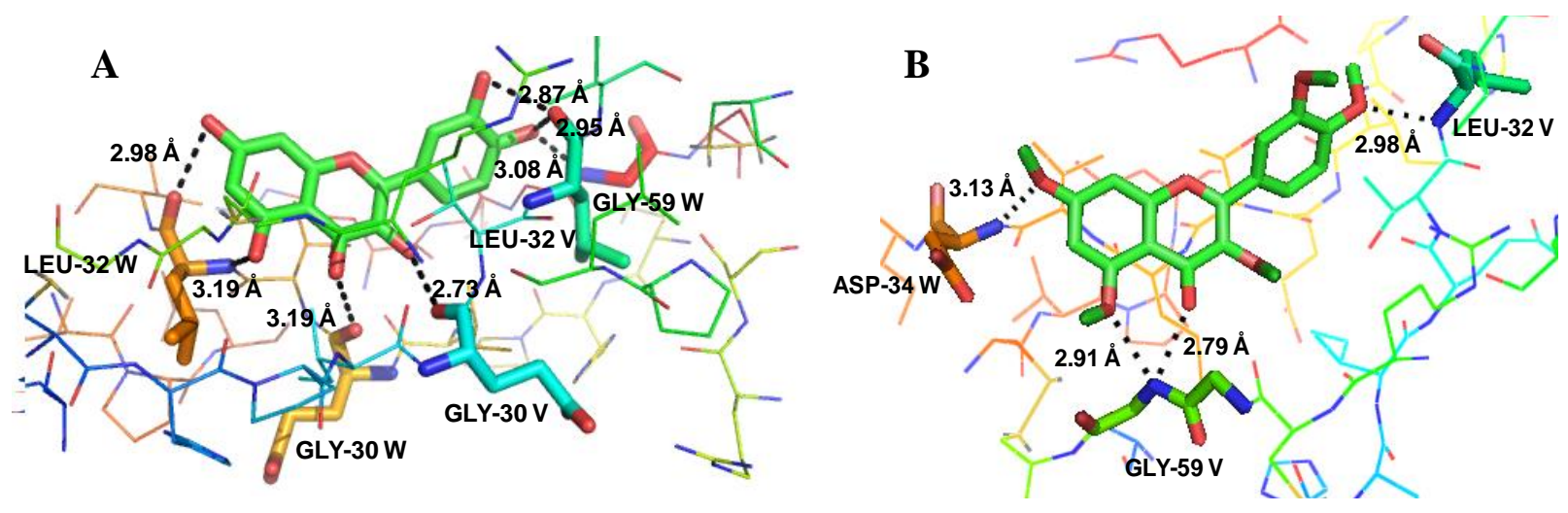


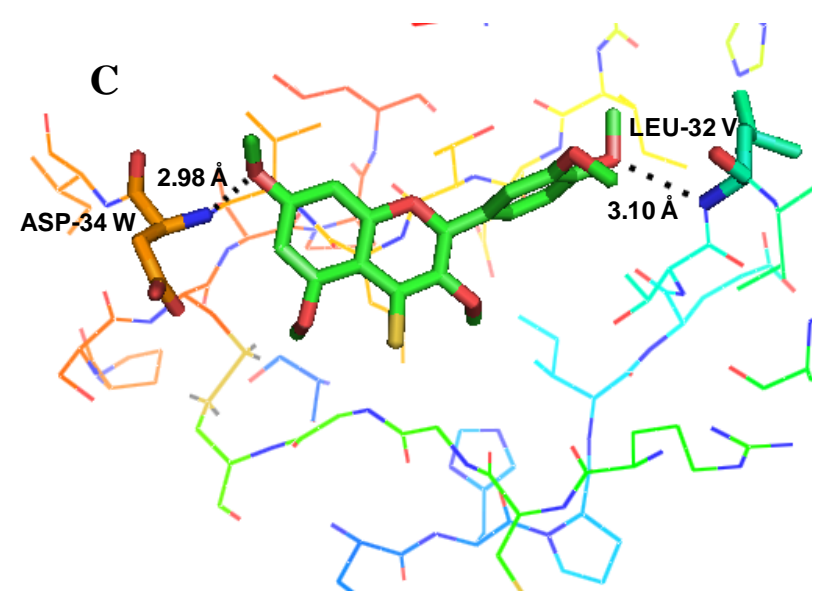

D
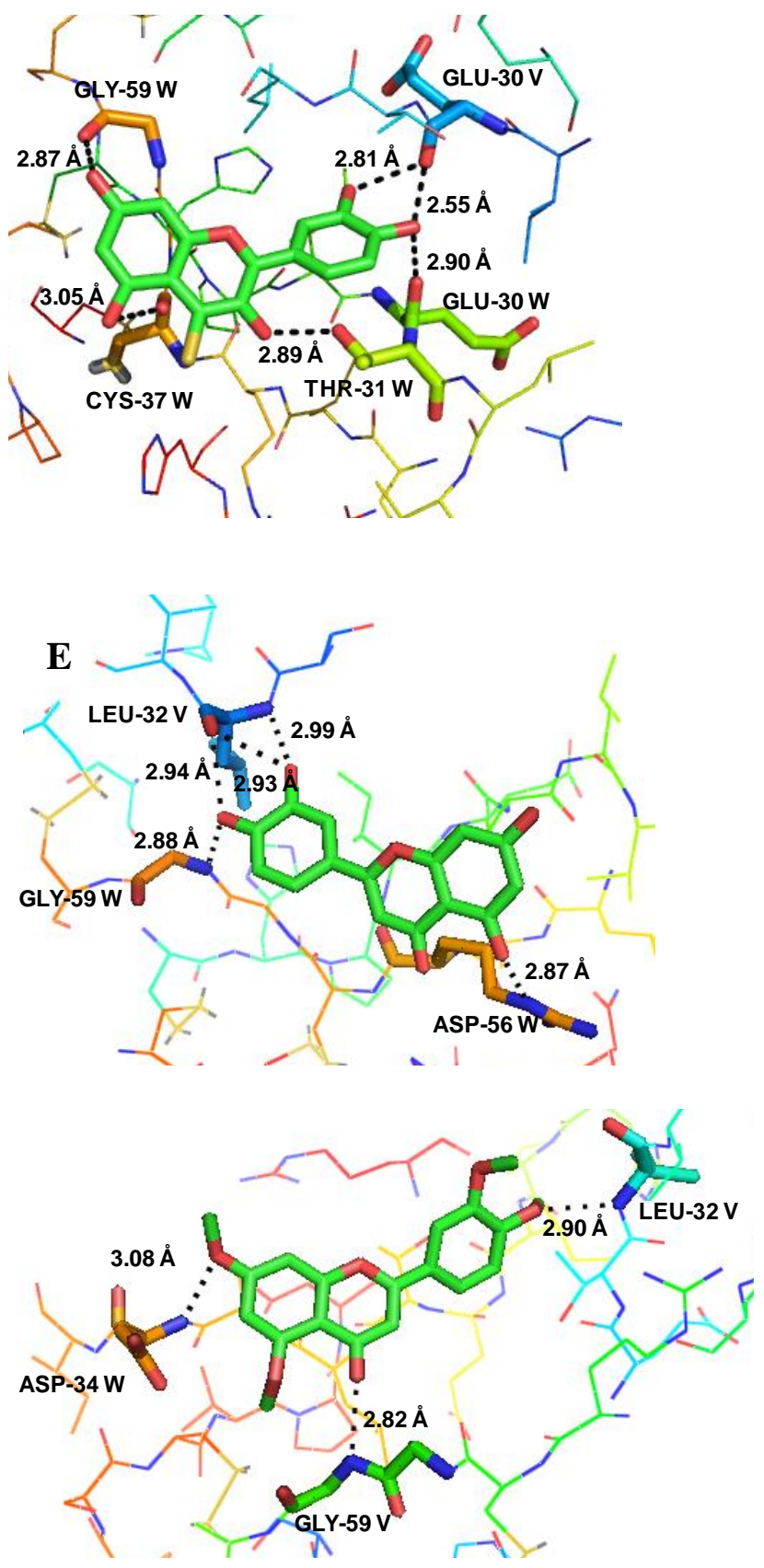


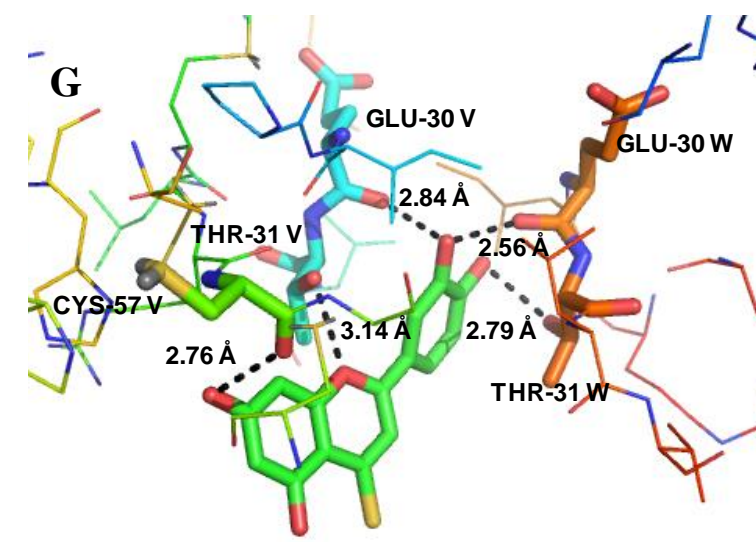

$\mathbf{H}$

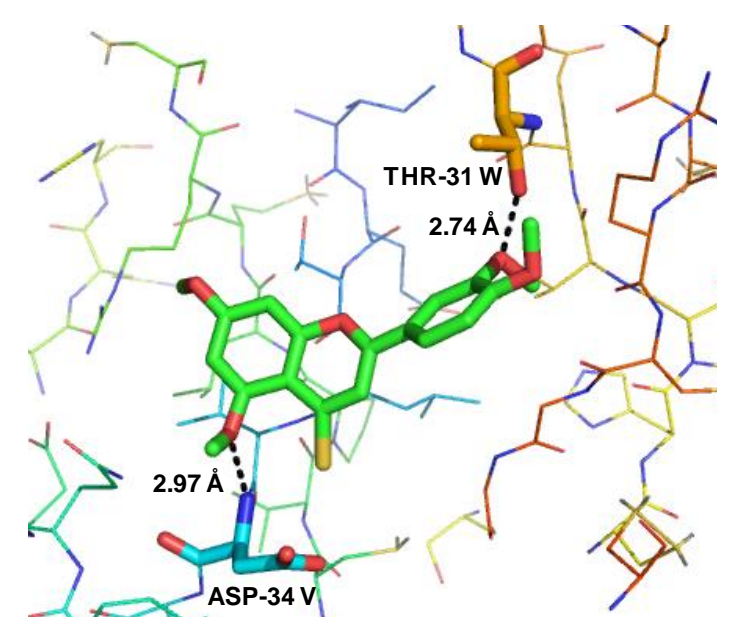

Figure 6. Docking modes of quercetin (1) (A), methoxy quercetin (2) (B), thiomethoxy quercetin (3) (C), thioquercetin (4) (D), luteolin (10) (E), methoxy luteolin (9) (F), thiomethoxy luteolin (11) (G), thioluteolin (12) (H) with VEGF.

\subsection{Membrane perturbation (probed by DSC)}

A recent paper by Ingólfsson et al. has provided new insight into how the biological effects of flavonoids might be explained [23]. The authors suggest that many of the biological activities triggered by flavonoids (more specifically, activation of certain membrane proteins) might, in fact, be the result of flavonoid-induced perturbation of biological membranes, rather than a direct ligand-receptor effect. The authors do not exclude the possibility of direct binding, but recommend ruling out bilayer effects first. Therefore, the 6 compounds (1-3 and 9-11), which showed VEGF/VEGFR mediated antiangiogenic activity (in the scratch assay and Western blotting) in our study, were further investigated for a possible lipid interaction (bilayer effect) 
with a dipalmitoylphosphatidylcholine bilayer [DPPC (lipid)] model using differential scanning calorimetry (DSC). In order to validate our system, genistein, which has been reported to perturb biological membranes by Ingolfsson et al. and has a structural similarity with our panel of compounds, was used as a positive control.

Dipalmitoylphosphatidylcholine (DPPC) alone (i.e. in the absence of genistein or any compounds) showed a pre transition $\left(\mathrm{T}_{\mathrm{p}}\right)$ centered at $36.25{ }^{\circ} \mathrm{C}$ and a main transition $\left(\mathrm{T}_{\mathrm{m}}\right)$ at $41.31{ }^{\circ} \mathrm{C}$. These data for the pure lipid system are in good agreement with previous reports [24,25] (Figure-7). Addition of genistein to the DPPC system showed perturbation of this lipid bilayer, as evidenced by a significant lowering of the $\mathrm{T}_{\mathrm{m}}$ (from $41.23{ }^{\circ} \mathrm{C}$ to $40.89{ }^{\circ} \mathrm{C}$ (at $60 \mu \mathrm{M}$ ) and to $40.51{ }^{\circ} \mathrm{C}$ (at $\left.100 \mu \mathrm{M}\right)$ ), as reported in Table-1 and Figure-7. No changes were observed with the $\Delta \mathrm{H}$ of the main transition temperature $\left(\Delta \mathrm{H}_{\mathrm{m}}\right)$ peak, but the $\mathrm{T}_{\mathrm{p}}$ peak broadened at $10 \mu \mathrm{M}$ and became undetectable at $60 \mu \mathrm{M}$ and $100 \mu \mathrm{M}$. The lowest concentration of genistein at which a membrane effect was observed $(60 \mu \mathrm{M})$ was in line with the concentrations at which genistein's bilayer effect had been reported by Ingolfsson et al [23], which indicated that the experimental system was fit for purpose and could be used to assess the potential bilayer effect of our compounds.

Quercetin and its derivatives: Unlike genistein, quercetin and its derivatives did not affect the $\mathrm{T}_{\mathrm{m}}$ at the concentration for which antiangiogenic activity was reported (10 $\left.\mu \mathrm{M}\right)$ (see supporting information) and, indeed, no significant effect was evident at 10 times that concentration (100 $\mu \mathrm{M}$ ) (see Table-1 and Figure-7). No change was observed for $\Delta \mathrm{H}_{\mathrm{m}}$ but the $\mathrm{T}_{\mathrm{p}}$ peak was affected ( $\mathrm{T}_{\mathrm{p}}$ was lowered along with the peak broadening). Others have suggested that the $\mathrm{T}_{\mathrm{p}}$ is highly sensitive to the presence of other molecules in the phospholipids and that changes in the pretransition of DSC profile cannot be attributed to any specific molecular changes [26]. Several studies have been reported on the interactions of quercetin with bilayer lipid membranes [27,28], 
mainly the study by Sinha et al. in which quercetin was reported to affect biological membranes primarily at concentrations 250 fold higher than those for which we are reporting activity [29].

Luteolin and its derivatives: When luteolin (10), methoxy luteolin (9) and thiomethoxy luteolin (11) were analysed, no changes in the DSC profile of DPPC was observed at the biologically active concentrations nor at 10 times that concentration.

Taken together, these results indicate that the antiangiogenic activity observed for the compounds studied herein is likely to be mediated via an interference with the VEGF/VEGFR signalling pathway, as evidenced by the Western blotting and computational studies, rather than being the result of membrane perturbation. This statement is certainly true for luteolin and its derivatives, for which no interactions were observed. The subtle membrane effect observed for quercetin and its derivatives does not appear to be sufficiently significant to explain the biological effects and dismiss a specific interaction with the VEGF/VEGFR system. 
A Positive Control (Genistein)

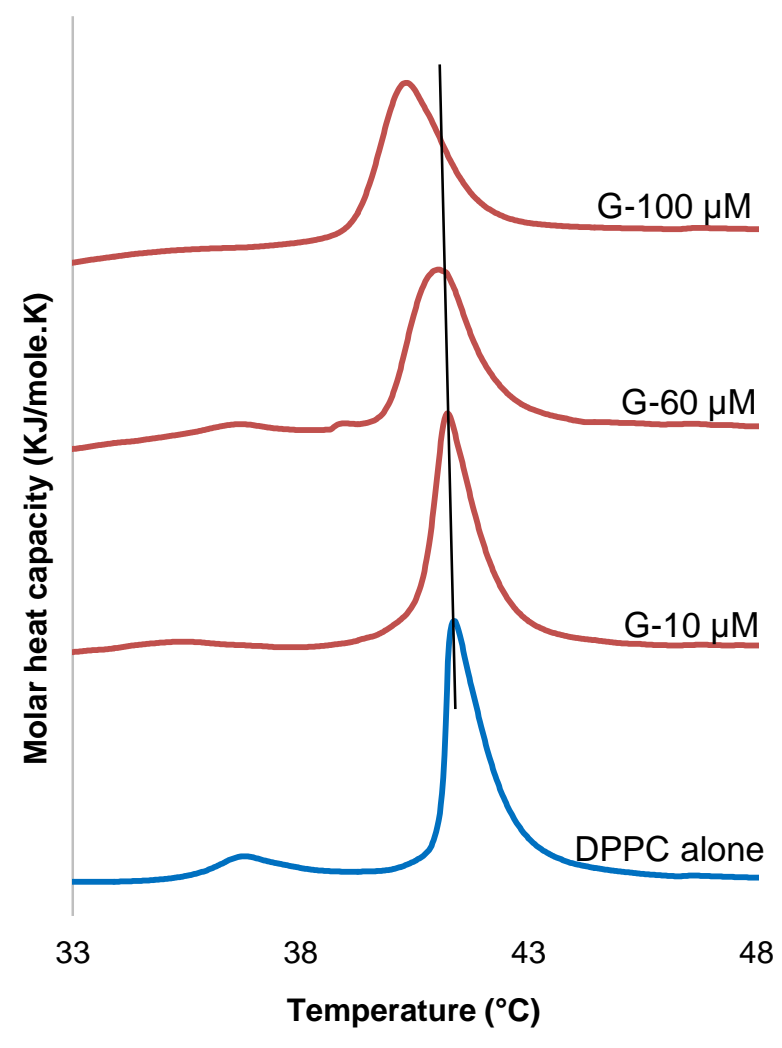


B

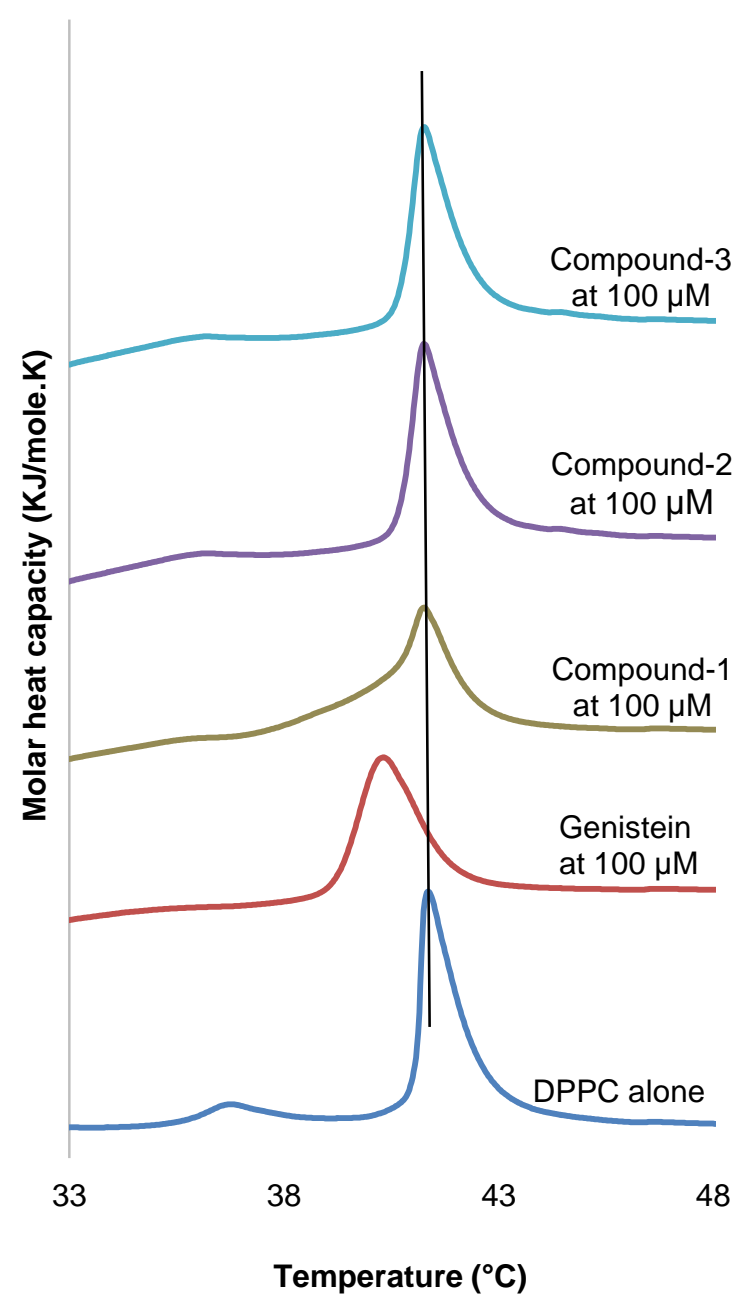

C Luteolin derivatives

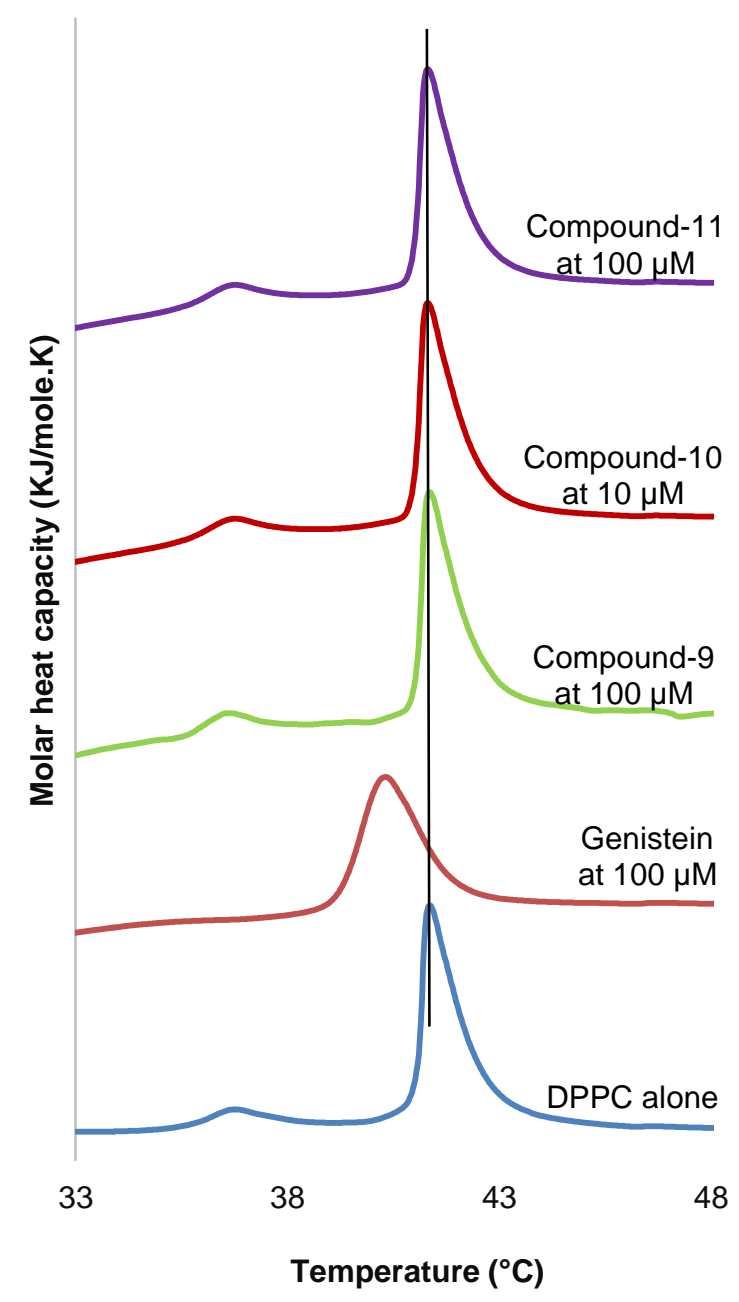

Figure 7. Representative DSC profiles of DPPC MLV's illustrating the effect in the presence of (A) Genistein at 10 $\mu \mathrm{M}(\mathrm{G}-10 \mu \mathrm{M}), 60 \mu \mathrm{M}(\mathrm{G}-60 \mu \mathrm{M})$, and $100 \mu \mathrm{M}(\mathrm{G}-100 \mu \mathrm{M})$ in comparison with DPPC alone; (B) Quercetin and its derivatives (at 10 times the concentration at which antiangiogenic effects were observed): compound-1 at $100 \mu \mathrm{M}$, compound-2 at $100 \mu \mathrm{M}$, compound-3 at $100 \mu \mathrm{M}$ in comparison with genistein at $100 \mu \mathrm{M}$ and DPPC alone; (C) Luteolin and its derivatives (at 10 times the concentration at which antiangiogenic effects were observed): compound-9 at $100 \mu \mathrm{M}$, compound-10 at $10 \mu \mathrm{M}$, compound-11 at $100 \mu \mathrm{M}$ in comparison with genistein at $100 \mu \mathrm{M}$ and DPPC alone.

Table 1. Thermodynamic parameters obtained by DSC for the interaction of DPPC with compounds 1-3 and 9-11

\begin{tabular}{ccccc}
\hline Compound & $\begin{array}{c}\text { Concentration } \\
(\boldsymbol{\mu M})\end{array}$ & $\begin{array}{c}\mathbf{T}_{\mathbf{p}} \\
\left({ }^{\circ} \mathbf{C}\right)\end{array}$ & $\begin{array}{c}\mathbf{T}_{\mathbf{m}} \\
\left({ }^{\circ} \mathbf{C}\right)\end{array}$ & $\begin{array}{c}\Delta \mathbf{H}_{\mathbf{m}} \\
(\mathbf{K J} / \mathbf{m o l})\end{array}$ \\
\hline & $0^{\mathrm{b}}$ & $36.25 \pm 0.33$ & $41.31 \pm 0.01$ & $23.03 \pm 0.56$ \\
Positive control & 10 & $35.28 \pm 0.10^{* *}$ & $41.23 \pm 0.01$ & $23.31 \pm 0.89$ \\
\cline { 5 - 6 }
\end{tabular}




\begin{tabular}{ccccc}
\hline Genistein & 60 & - & $40.89 \pm 0.09^{*}$ & $22.90 \pm 0.89$ \\
& 100 & - & $40.51 \pm 0.12^{* * * *}$ & $23.10 \pm 0.78$ \\
\hline \multirow{2}{*}{ Compound-1 } & $0^{\mathrm{b}}$ & $36.25 \pm 0.33$ & $41.31 \pm 0.01$ & $23.03 \pm 0.56$ \\
& 10 & $35.65 \pm 0.18^{*}$ & $41.28 \pm 0.02$ & $23.09 \pm 0.86$ \\
Compound-2 & 100 & - & $41.26 \pm 0.01$ & $22.98 \pm 0.45$ \\
\hline \multirow{2}{*}{ Compound-3 } & $0^{\mathrm{b}}$ & $36.25 \pm 0.33$ & $41.31 \pm 0.01$ & $23.03 \pm 0.56$ \\
& 10 & $35.58 \pm 0.15^{*}$ & $41.29 \pm 0.01$ & $22.80 \pm 0.76$ \\
& 100 & - & $41.15 \pm 0.01$ & $22.91 \pm 0.55$ \\
\hline \multirow{2}{*}{ Compound-9 } & $0^{\mathrm{b}}$ & $36.25 \pm 0.33$ & $41.31 \pm 0.01$ & $23.03 \pm 0.56$ \\
& 10 & $35.70 \pm 0.05^{*}$ & $41.25 \pm 0.01$ & $23.08 \pm 1.04$ \\
& 100 & - & $41.20 \pm 0.01$ & $23.28 \pm 0.32$ \\
\hline \multirow{2}{*}{ Compound-10 } & $0^{\mathrm{b}}$ & $36.25 \pm 0.33$ & $41.31 \pm 0.01$ & $23.03 \pm 0.56$ \\
& 10 & $36.52 \pm 0.03$ & $41.26 \pm 0.02$ & $22.56 \pm 0.65$ \\
& 100 & $36.54 \pm 0.02$ & $41.30 \pm 0.03$ & $22.35 \pm 0.46$ \\
\hline \multirow{2}{*}{ Compound-11 } & $0^{\mathrm{b}}$ & $36.25 \pm 0.33$ & $41.31 \pm 0.01$ & $23.03 \pm 0.56$ \\
& 10 & $36.43 \pm 0.04$ & $41.30 \pm 0.01$ & $22.79 \pm 0.84$ \\
& 100 & - & $41.32 \pm 0.01$ & $21.68 \pm 0.32$ \\
\hline Dannyy & 10 & $36.62 \pm 0.05$ & $41.33 \pm 0.01$ & $23.81 \pm 0.97$ \\
& 100 & $36.61 \pm 0.01$ & $41.31 \pm 0.01$ & $23.34 \pm 0.73$ \\
\hline
\end{tabular}

${ }^{\mathrm{a}}$ Data are expressed as the mean \pm standard error of the mean (SEM), $\mathrm{n}=3 .{ }^{\mathrm{b}} 0 \mu \mathrm{M}$ corresponds to plain DPPC (without any additive). $\mathrm{T}_{\mathrm{p}}$ - Pre-transition temperature, $\mathrm{T}_{\mathrm{m}}$ - Main transition temperature, $\Delta \mathrm{H}_{\mathrm{m}}$ - Enthalpy change of the main transition peak. Statistical significance was estimated vs the control (DPPC alone, i.e. $0 \mu \mathrm{M}$ ) by one-way ANOVA, followed by Bonferroni's post hoc test $\left({ }^{*} \mathrm{p}<0.05, * * \mathrm{p}<0.01\right.$ and $\left.* * * * \mathrm{p}<0.0001\right)$.

\subsection{Antiproliferative activity}

The flavonoids are known to exhibit a direct antiproliferative effect on various tumour cells [6] including hormone dependent cancers such as MCF-7 breast cancer cell line. Therefore, we considered MCF-7 as an appropriate model to assess the antiproliferative activity of the compounds prepared herein. Hence, in this study, the direct inhibitory effects of quercetin and luteolin derivatives were determined against the breast cancer cell line MCF-7 (wild type) and its doxorubicin-resistant cell line MCF-7/DX to compare their concentrations that are required to elicit the direct anticancer activity and the antiangiogenic activity. Cell viabilities were determined in the presence and the absence of quercetin, luteolin and their derivatives by MTT assay [30] after $72 \mathrm{~h}$ incubation. The cytotoxicity profiles and the $\mathrm{IC}_{50}$ values of these compounds are shown in Figure-8 and Table-2 respectively. 
Among quercetin and its derivatives, only compound-1 was found to be antiproliferative with $\mathrm{IC}_{50}$ values of $13.7 \pm 0.61 \mu \mathrm{M}$ and $80.4 \pm 1.79 \mu \mathrm{M}$ against MCF-7 cell line and MCF-7/DX cell line respectively. The methoxy and the 4-thio derivative, compounds-2 and 4 respectively displayed their antiproliferative activity at concentrations greater than $100 \mu \mathrm{M}$, whereas the 4thiomethoxy derivative, compound-3 did not demonstrate any cytotoxicity below $250 \mu \mathrm{M}$ concentration. Thus, the antiproliferative activities of quercetin and its derivatives are in the order of compound-1>compound-4>compound-2>compound-3. Among luteolin and its derivatives, compounds-10 and $\mathbf{1 2}$ were found to be active with $\mathrm{IC}_{50}$ values of $21.6 \pm 0.81 \mu \mathrm{M}$ and $27.3 \pm 1.55 \mu \mathrm{M}$ respectively against MCF-7 cell line and 81.1 $\pm 1.79 \mu \mathrm{M}$ and $75.9 \pm 3.08$ $\mu \mathrm{M}$ respectively against MCF-7/DX cell line. However, compounds 9 and $\mathbf{1 1}$ did not demonstrate any antiproliferative activity below $250 \mu \mathrm{M}$ concentration. Therefore, the antiproliferative activities of luteolin and its derivatives are in the order of compound$\mathbf{1 0} \geq$ compound-12>compound-9$\equiv$ compound-11. In general, the antiproliferative activities of these compounds suggest that the methoxy and the thiomethoxy derivatives are 10-15 fold less active than their parent compounds.
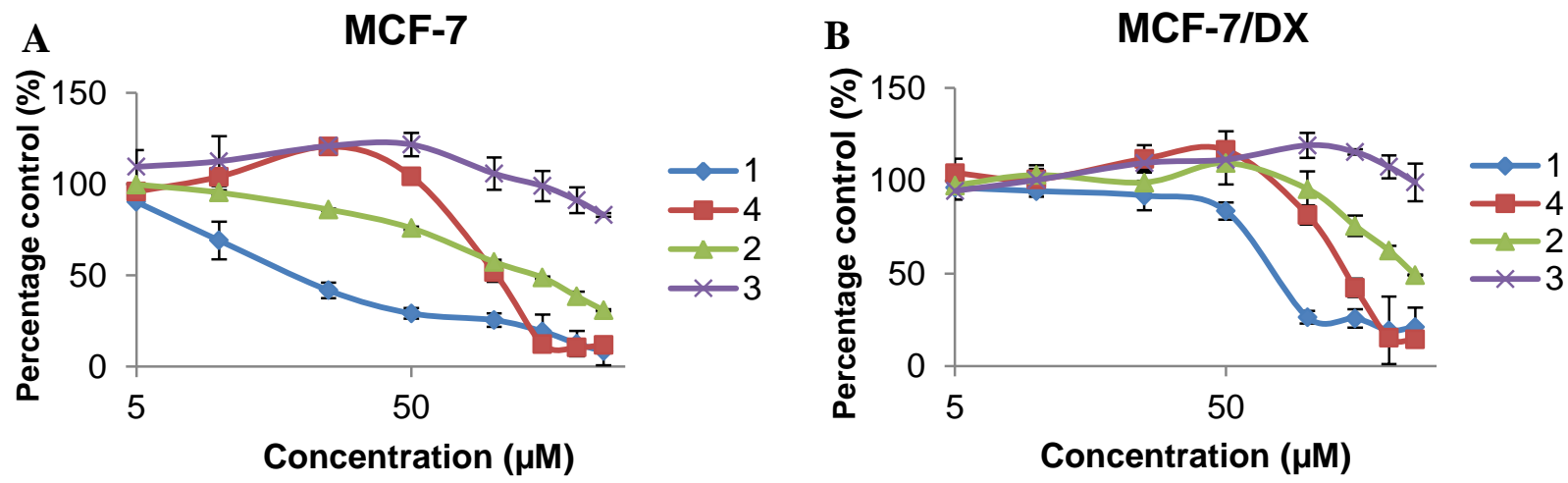

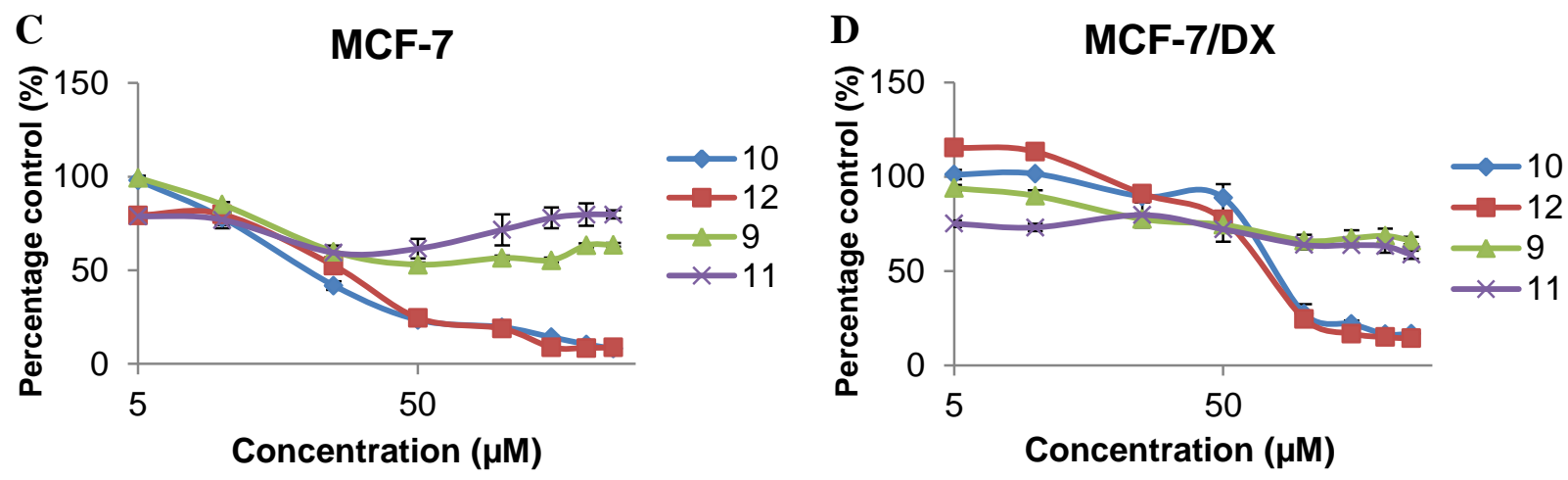

Figure 8. Dose-dependent cytotoxicity curves of quercetin (1), thioquercetin (4), methoxy quercetin (2) and thiomethoxy quercetin (3) (A) against MCF-7 (B) against MCF-7/DX. Dose-dependent cytotoxicity curves of luteolin (10), thioluteolin (12) methoxyluteolin (9) and thiomethoxyluteolin (11) (C) against MCF-7 (D) against MCF-7/DX. Data are expressed as the mean \pm standard error of the mean $(\mathrm{SEM}), \mathrm{n}=3$.

Table 2- $\mathrm{IC}_{50}$ values of quercetin, luteolin and their derivatives.

\begin{tabular}{|c|c|c|c|c|}
\hline $\begin{array}{l}\text { Chemical } \\
\text { structure }\end{array}$ & Compound & Substitution & $\mathrm{IC}_{50}$ in MCF-7 & $\mathrm{IC}_{50}$ in $\mathrm{MCF}-7 / \mathrm{DX}$ \\
\hline & 1 & $\mathrm{R}^{1,2,3,4,5}=\mathrm{OH}, \mathrm{X}=\mathrm{O}$ & $13.7 \pm 0.61 \mu \mathrm{M}$ & $80.4 \pm 1.79 \mu \mathrm{M}$ \\
\hline & 4 & $\mathrm{R}^{1,2,3,4,5}=\mathrm{OH}, \mathrm{X}=\mathrm{S}$ & $102.6 \pm 5.36 \mu \mathrm{M}$ & $139.3 \pm 6.89 \mu \mathrm{M}$ \\
\hline & 2 & $\mathrm{R}^{1,2,3,4,5}=\mathrm{OMe}, \mathrm{X}=\mathrm{O}$ & $140 \pm 1.63 \mu \mathrm{M}$ & $245.1 \pm 2.53 \mu \mathrm{M}$ \\
\hline & 3 & $\mathrm{R}^{1,2,3,4,5}=\mathrm{OMe}, \mathrm{X}=\mathrm{S}$ & $>250 \mu \mathrm{M}$ & $>250 \mu \mathrm{M}$ \\
\hline & 10 & $\mathrm{R}^{1,2,3,4}=\mathrm{OH}, \mathrm{X}=\mathrm{O}$ & $21.6 \pm 0.81 \mu \mathrm{M}$ & $81.1 \pm 1.79 \mu \mathrm{M}$ \\
\hline & 12 & $\mathrm{R}^{1,2,3,4}=\mathrm{OH}, \mathrm{X}=\mathrm{S}$ & $27.3 \pm 1.55 \mu \mathrm{M}$ & $75.9 \pm 3.08 \mu \mathrm{M}$ \\
\hline & 9 & $\mathrm{R}^{1,2,3,4}=\mathrm{OMe}, \mathrm{X}=\mathrm{O}$ & $>250 \mu \mathrm{M}$ & $>250 \mu \mathrm{M}$ \\
\hline & 11 & $\mathrm{R}^{1,2,3,4}=\mathrm{OMe}, \mathrm{X}=\mathrm{S}$ & $>250 \mu \mathrm{M}$ & $>250 \mu \mathrm{M}$ \\
\hline
\end{tabular}

\subsection{Considerations of the structure-activity relationships (SARs)}

Comparison of the antiangiogenic activities and antiproliferative activities of quercetin, luteolin and their derivatives has led to identification of the key structural features that are specific for an enhanced and a selective antiangiogenic activity. Comparison of the antiangiogenic activities of underivatised quercetin $(\mathbf{1}$, bearing 5 hydroxyls, $4-\mathrm{C}=\mathrm{O})$ with underivatised luteolin $(\mathbf{1 0}$, bearing 4 hydroxyls, 4-C=O) indicates that luteolin without the $\mathrm{C}-3$ hydroxyl has a higher antiangiogenic potential $(86 \%$ versus $54 \%$ inhibition of VEGF stimulated migration at $1 \mu \mathrm{M}$ concentration). This observation is consistent with the Western blotting analysis, which showed 
increased inhibition of autophosphorylation of VEGFR2 in presence of luteolin $(1 \mu \mathrm{M})$. Docking studies also suggested greater binding affinity of luteolin (docking score-6.87) with VEGFR2 than quercetin (docking score-6.56). These observations suggest that the C-3 hydroxyl is not important for the antiangiogenic activity. However, for their methoxy derivatives (-OMe and 4-C=O), it was observed that the methoxy derivative of quercetin containing a $\mathrm{C}-3$ methoxy group has a greater potency to inhibit VEGF stimulated migration $(86 \%$ at $10 \mu \mathrm{M})$ through the inhibition of VEGF mediated autophosphorylation at Tyr-1175 site than the methoxy analogue of luteolin (9) as well as the hydroxy analogues quercetin and luteolin. Docking studies also indicated the highest binding affinity of compound-2 with both VEGFR2 and VEGF, and also it was observed that the enhanced antiangiogenic activity of compound-2 is due to the enhanced hydrophobic interactions formed by of C-3 -OMe group with the VEGFR2. This demonstrates that the presence of a C-3 -OMe group is beneficial for the antiangiogenic activity.

Similarly, comparison of the antiangiogenic activities of compounds containing the $4-\mathrm{C}=\mathrm{O}$ functionality $(\mathbf{1}, \mathbf{2}, 9$ and 10) with the derivatives containing the $4-\mathrm{C}=\mathrm{S}$ functionality $(\mathbf{3}, \mathbf{4}, 11$ and 12) indicated that replacement of the $4-\mathrm{C}=\mathrm{O}$ group with a $4-\mathrm{C}=\mathrm{S}$ resulted in a weaker in vitro inhibition of VEGF-stimulated migration, especially for $4-\mathrm{C}=\mathrm{S}$ compounds with the free hydroxyl groups (4 and 12). Hence, conversion of the 4-C=O to $4-\mathrm{C}=\mathrm{S}$ group is detrimental to the antiangiogenic activities of both quercetin and luteolin. This observation is further supported by the Western blotting studies that illustrate very poor inhibition of autophosphorylation of VEGFR2, and also by the molecular docking studies that show weaker interactions with VEGFR2 and VEGF, by these 4-C=S derivatised compounds. Collectively, these results suggest that the 4-C $=\mathrm{O}$ moiety is crucial for antiangiogenic activity.

From the comparison of the antiproliferative and the antiangiogenic activities of quercetin, luteolin and their derivatives, it is interesting to note that the derivatives with higher 
antiangiogenic properties were generally less cytotoxic than those with lower antiangiogenic properties. This would be an attractive feature of these derivatives for use in future clinical development as they could potentially be used for their anti-angiogenic properties at concentrations significantly lower than those required for a direct anticancer activity. Thus comparison of the antiproliferative activities of quercetin and luteolin with their methoxy, 4thiomethoxy and 4-thiohydroxy derivatives illustrates that methylation of the free hydroxyls and replacement of the $4-\mathrm{C}=\mathrm{O}$ group with a $4-\mathrm{C}=\mathrm{S}$ group decreases the antiproliferative activity. In the case of quercetin, methylation of the hydroxyl group resulted in a 10-18 fold decrease in the antiproliferative potency. A similar trend was observed in the case of luteolin where an approximately 11 fold decline in antiproliferative activity was observed for its methoxy derivative. Replacement of the $4-\mathrm{C}=\mathrm{O}$ group with a $4-\mathrm{C}=\mathrm{S}$ group in the case of quercetin has also shown a detrimental impact on the antiproliferative activity with the 4-thio derivative showing about 8 fold less reactivity than quercetin. However, in the case of luteolin, the conversion of the $4-\mathrm{C}=\mathrm{O}$ group to the $4-\mathrm{C}=\mathrm{S}$ group has not impacted on the antiproliferative property with both luteolin and its 4-thio derivative exhibiting similar cytotoxicity profiles. This suggests that methylation of the free hydroxyl groups in flavonoids allows selective antiangiogenic activity. Figure-9 presents the SAR observed for the quercetin and luteolin derivatives.

Overall, methoxyquercetin (2) and luteolin (10) possess higher potency to prevent VEGF driven HUVEC migration at a 10 and 20 fold lower concentration respectively than the concentration that is required to directly inhibit the in vitro proliferation of tumour cells. This could be attributed to the high degree of selectivity of this compound for the inhibition of VEGFR2 versus a range of other kinases [31]. 
As the clinical outcomes of the current antiangiogenic therapy and preclinical studies have suggested the need for co-administration of the inhibitors with chemotherapeutics, for continual constraint of angiogenesis [32-34], molecules with an appropriate balance of high potency against VEGFR2 and minimal toxicity are preferred. Therefore, with the view of developing antiangiogenic agents for cancer therapeutics and combination therapy, our present work suggests compound-2 and compound-10 as potential leads for further optimisation and development.

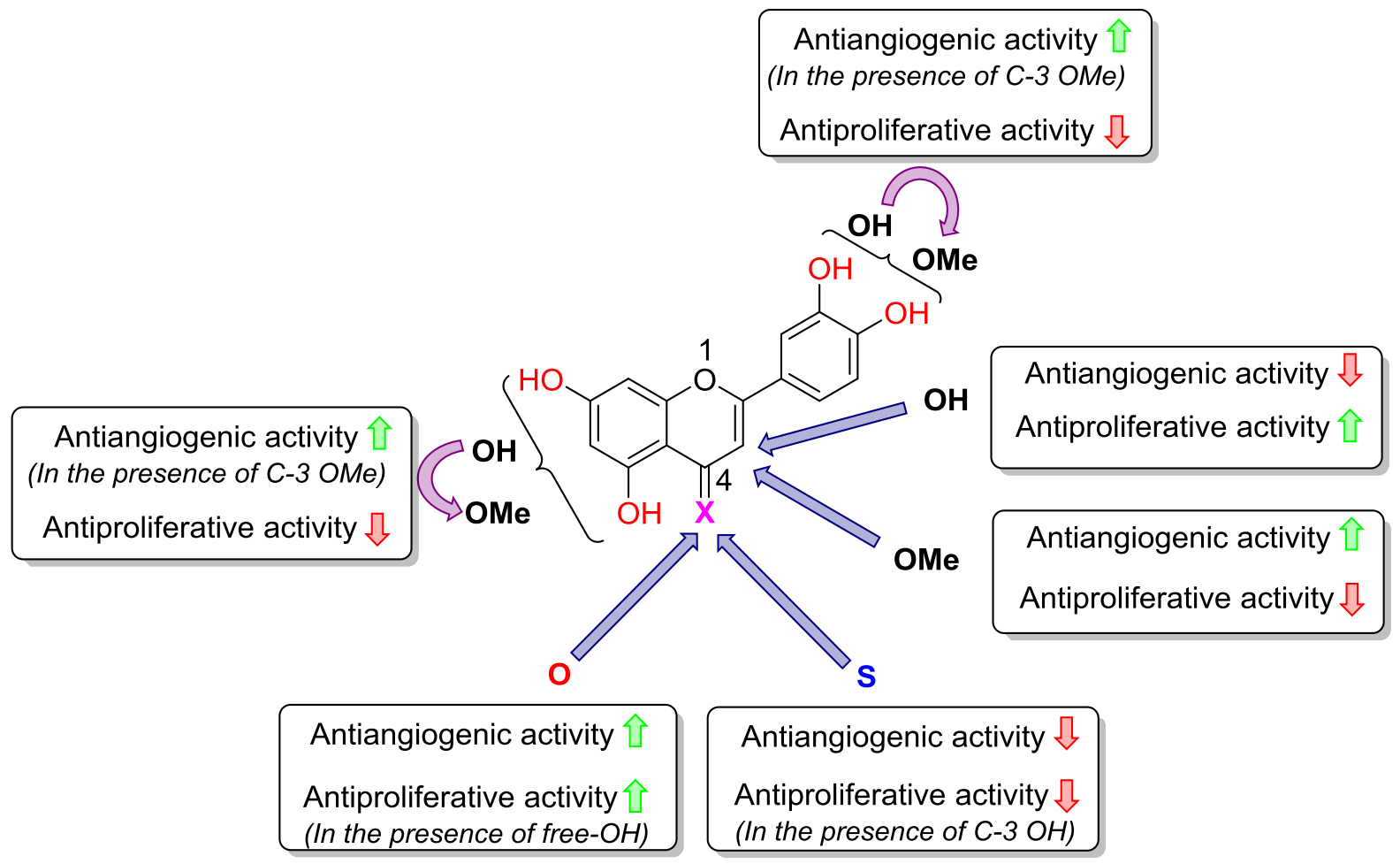

Figure 9. General SAR of quercetin and luteolin derivatives

\section{CONCLUSION}

In conclusion, we have synthesised the methoxy and 4-thio derivatives of quercetin and luteolin and evaluated their resulting antiangiogenic and antiproliferative potencies, alongside quercetin and luteolin. As part of this programme we have demonstrated the impact of subtle structural modifications such as methylation and 4-thio conversion on the antiangiogenic and antiproliferative properties of quercetin and luteolin. Comparison of their antiangiogenic 
activities has led to identification of key structural features required for the antiangiogenic activities. It was found that the 4- $\mathrm{C}=\mathrm{O}$ functionality is crucial for the antiangiogenic activity and also methylation of the free hydroxyl groups provides the benefit of potential antiangiogenic activity with low cytotoxicity. Also, analysis of bilayer membrane interactions of the active compounds suggests that bilayer effects do not play a significant role in the biological mechanism of action at the concentrations tested, especially for luteolin and its derivatives. Among quercetin, luteolin and their derivatives, compound-2 and compound-10 were found to potentially inhibit the in vitro VEGF induced cell migration with low cytotoxicity. In addition, the molecular docking studies indicated that compound-2 and compound-10 possess high binding affinities towards VEGF and VEGFR2. Overall, compound-2 and compound-10 exhibit an appropriate balance of high antiangiogenic activity and minimal toxicity. Therefore, they have been identified as the most promising flavonoid templates from our programme of study for further development as antiangiogenic agents.

\section{EXPERIMENTAL SECTION}

\subsection{Materials and Methods}

Chemicals and Reagents: All chemicals were purchased from Sigma-Aldrich unless specified. 2-hydroxy-4,6-dimethoxyacetophenone was purchased from Alfa Aesar, UK and quercetin was purchased from Sigma-Aldrich, UK. Solvents were purchased from Fisher Scientific, UK and

Sigma Aldrich, UK. ${ }^{1} \mathrm{H}-\mathrm{NMR}$ and ${ }^{13} \mathrm{C}-\mathrm{NMR}$ spectra were recorded in either deuterated chloroform $\left(\mathrm{CDCl}_{3}\right)$, deutereated dimethyl sulfoxide (DMSO-d6) using a Bruker DPX 400 (400 MHz) spectrometer. Mass spectrometry data were recorded on a Thermo Fisher LTQ Orbitrap XL instrument. A HPLC (Agilent-1100 series) equipped with Column: C-18 (ACE-221-2546; $4.6 \mathrm{~mm} \times 250 \mathrm{~mm} ; 5 \mu \mathrm{m}) ; 1.0 \mathrm{~mL} / \mathrm{min}$ flow rate; $20 \mathrm{~min}$ gradient of $1 \%$ acetic acid in acetonitrile [organic mobile phase (A)] and 1\% acetic acid in water [aqueous mobile phase (B)] 
from $5 \% \mathrm{~A}$ at $0 \mathrm{~min}, 20 \% \mathrm{~A}$ at $2 \mathrm{~min}, 40 \% \mathrm{~A}$ at $6 \mathrm{~min}, 60 \% \mathrm{~A}$ at $8 \mathrm{~min}, 95 \% \mathrm{~A}$ at $10 \mathrm{~min}, 5 \% \mathrm{~A}$ at $20 \mathrm{~min}$, at $258 \mathrm{~nm}$ was used to determine the purity of all the synthesised compounds.

Cell line and Culture: HUVECs were purchased from ECACC and cultured in EGM-2 medium. MCF-7 (ER +ve breast cancer cell line, wild type) and MCF-7/DX (ER + ve breast cancer cell line, doxorubicin resistant type) were provided by Tenovus centre for Cancer research (Cardiff, UK). Both MCF-7 and MCF-7/DX cells were cultured in RPMI 1640 supplemented with 5\% fetal bovine serum. All the culture media and other reagents were obtained from Lonza, UK. Bovine serum albumin (BSA) was purchased from Sigma Aldrich, UK. Recombinant human VEGFR-A 165 was purchased from Peprotech, UK. The primary antibodies directed against phosphorylated tyrosine-1175 site in the VEGFR2 (KDR) was purchased from Cell signalling, UK. The primary antibody directed against total VEGFR2 was purchased from Santa Cruz Biotechnology, UK and the primary antibody directed against actin was purchased from Abcam, UK. Horseradish peroxidase-conjugated secondary antibody was purchased from Abcam, UK. Enhanced chemiluminescences (ECL) detection solutions were purchased from Bio-Rad, UK. PVDF membrane was purchased from Bio-Rad, UK. Reagents for Phosphate buffered saline (PBS) for cell culture were purchased from Sigma Aldrich, UK. PBS (pH 7.4) was freshly prepared in lab and solution $\mathrm{pH}$ was checked before used. Scratch assay images were captured using 1.3M microscope digital eyepiece camera. ImageJ software was used to quantify the cell migration.

The stock solutions of the test compounds $(10 \mathrm{mg} / \mathrm{mL})$ were prepared in sterile DMSO and ethanol $(1: 1 \mathrm{v} / \mathrm{v})$. These stocks were then appropriately diluted with the complete culture medium and the ethanol and DMSO levels were maintained below $1 \%$ in the test concentrations. 
Statistics analysis: Statistical analysis was carried out against the control groupby one-way ANOVA followed by Bonferroni's post hoc test using GraphpadPrism 6. Statistical significance value was set at $\mathrm{p}<0.05$. 


\subsubsection{Synthesis of methoxy and 4-thio methoxy quercetin (2-4)}

\subsubsection{Synthesis of 2-(3,4-dimethoxyphenyl)-3,5,7-trimethoxy-4H-chromen-4-one (2)}

Quercetin (1) (1g, $3.30 \mathrm{mmol})$ was dissolved in $\mathrm{KOH}(15 \%, 10 \mathrm{~mL})$ at ambient temperature. Dimethyl sulfate (2.29 g, $1.7 \mathrm{~mL}, 18.15 \mathrm{mmol}, 5.5$ eq., d=1.33 g/mL) was added slowly over 10 min and the reaction was stirred at ambient temperature for $1 \mathrm{~h}$. After $1 \mathrm{~h}$, further dimethyl sulfate (5.5 eq.) and $\mathrm{KOH}(15 \%, 10 \mathrm{~mL})$ were added and the mixture was heated to $90{ }^{\circ} \mathrm{C}$. After $3 \mathrm{~h}$, further dimethyl sulfate (5.5 eq.) and $\mathrm{KOH}(15 \%, 10 \mathrm{~mL})$ were added and the reaction was stirred overnight at $90{ }^{\circ} \mathrm{C} . \mathrm{KOH}(15 \%, 15 \mathrm{~mL})$ was then added and the reaction was stirred for another $5 \mathrm{~h}$ at $90{ }^{\circ} \mathrm{C}$. The reaction was cooled to room temperature, and acidified to $\mathrm{pH} 5$ by the addition of $2 \mathrm{M} \mathrm{HCl}(20 \mathrm{~mL})$. The precipitate was filtered and washed with water. The 2-(3,4dimethoxyphenyl)-3,5,7-trimethoxy-4H-chromen-4-one (2) was obtained as an off white solid in a pure form after purification by column chromatography [Solvent system: EtOAc (100\%)].

Yield: $60 \%$; m.p: $155-7{ }^{\circ} \mathrm{C}$ (lit [35]-150-52 ${ }^{\circ} \mathrm{C}$ ); ${ }^{\mathbf{1}} \mathbf{H}$ NMR: (DMSO-d6,400 MHz) $\delta 3.88,3.90$, $3.96\left(15 \mathrm{H}, \mathrm{s},-\mathrm{OCH}_{3}\right), 6.34(1 \mathrm{H}, \mathrm{s}, \mathrm{H}-6), 6.50(1 \mathrm{H}, \mathrm{s}, \mathrm{H}-8), 6.97(1 \mathrm{H}, \mathrm{d}, J=8.0 \mathrm{~Hz}, \mathrm{H}-5$ '), 7.69 $\left(1 \mathrm{H}, \mathrm{d}, J=8.0 \mathrm{~Hz}, \mathrm{H}-6^{\prime}\right), 7.71\left(1 \mathrm{H}, \mathrm{s}, \mathrm{H}-2^{\prime}\right) ;{ }^{13}$ C NMR: (DMSO-d6, $\left.100 \mathrm{MHz}\right) \delta 56.3(4 \mathrm{x}-$ $\left.\mathrm{OCH}_{3}\right), 59.9\left(-\mathrm{OCH}_{3}\right), 92.3(\mathrm{C} 8), 95.8$ (C6), $109.4(\mathrm{C} 10), 110.7$ (C2'), $111.5(\mathrm{C} 5$ ') 121.6 (C6'), 123.7 (C1'), 141.3 (C3), 148.8 (C4'), 150.8 (C3’), 152.6 (C2), 158.9 (C9), 161.3 (C5), 164.1 (C7), $174.0(\mathbf{C}=\mathrm{O}) ; \mathbf{I R} \boldsymbol{v}_{\max }\left[\mathbf{c m}^{-1}\right]: 1651(\mathrm{C}=\mathrm{O}, v, \mathrm{~s}), 1291\left(-\mathrm{OCH}_{3}, v, \mathrm{~s}\right), 1097(\mathrm{C}-\mathrm{O}, \mathrm{v}, \mathrm{m}) ; \boldsymbol{m} / \boldsymbol{z}$ (FTMS+ESI): $\mathrm{M}+\mathrm{H}\left(\mathrm{C}_{20} \mathrm{H}_{21} \mathrm{O}_{7}\right)$ requires 373.1282, found 373.1277. HPLC purity: $96.1 \%$

\subsubsection{Synthesis of 2-(3,4-dimethoxyphenyl)-3,5,7-trimethoxy-4H-chromene-4-thione (3)}

2-(3,4-Dimethoxyphenyl)-3,5,7-trimethoxy-4H-chromen-4-one (2) (0.20 g, $0.53 \mathrm{mmol})$ was dissolved in anhydrous toluene $(1 \mathrm{~mL})$, and Lawesson's reagent $(0.21,0.53 \mathrm{mmol}, 1$ eq.) was added and the reaction was heated to $110{ }^{\circ} \mathrm{C}$ for $4 \mathrm{~h}$. The reaction mixture was cooled to room temperature and concentrated in vacuo. The residue was purified by column chromatography 
[Solvent system: $\mathrm{CHCl}_{3}(100 \%)$ ] to obtain the pure 2-(3,4-Dimethoxyphenyl)-3,5,7-trimethoxy4H-chromene-4-thione (3) as a brown solid.

Yield: $65 \%$; m.p: $168-70{ }^{\circ} \mathrm{C}$ (lit [36]-170 $\left.{ }^{\circ} \mathrm{C}\right) ;{ }^{1} \mathbf{H}$ NMR: $\left(\mathrm{CDCl}_{3}, 400 \mathrm{MHz}\right) \delta 3.72(3 \mathrm{H}, \mathrm{s}$, $\left.\mathrm{OCH}_{3}\right), 3.95,3.93,3.07,4.03\left(12 \mathrm{H}, \mathrm{s}, 4 \mathrm{x}-\mathrm{OCH}_{3}\right), 6.42(1 \mathrm{H}, \mathrm{s}, \mathrm{H}-6), 6.54(1 \mathrm{H}, \mathrm{s}, \mathrm{H}-8), 7.00$ $\left(1 \mathrm{H}, \mathrm{d}, J=8.5 \mathrm{~Hz}, \mathrm{H}-5^{\prime}\right), 7.78\left(1 \mathrm{H}, \mathrm{d}, J=8.5 \mathrm{~Hz}, \mathrm{H}-6^{\prime}\right), 7.86\left(1 \mathrm{H}, \mathrm{s}, \mathrm{H}-2^{\prime}\right) ;{ }^{13} \mathbf{C}^{\prime} \mathbf{N M R}:\left(\mathrm{CDCl}_{3}\right.$, $100 \mathrm{MHz}) \delta 56.0\left(-\mathrm{OCH}_{3}\right), 58.7\left(-\mathrm{OCH}_{3}\right), 92.3(\mathrm{C} 8), 96.7(\mathrm{C} 6), 110.6\left(\mathrm{C} 2\right.$ '), $111.6\left(\mathrm{C}^{\prime}\right.$ '), 116.8 (C10), 122.0 (C6'), 123.2 (C1'), 146.3 (C3), 148.6 (C4'), 149.6 (C3’), 151.2 (C2), 154.4 (C9), $161.6(\mathrm{C} 7), 163.5(\mathrm{C} 5), 194.0(\mathbf{C}=\mathrm{S}) ; \mathbf{I R} \boldsymbol{v}_{\max }\left[\mathbf{c m}^{-1}\right]: 1351(\mathrm{C}=\mathrm{S}, \mathrm{v}, \mathrm{m}), 1220\left(-\mathrm{OCH}_{3}, v, \mathrm{~m}\right)$ $1143(\mathrm{C}-\mathrm{O}, v, \mathrm{~m}) ; \boldsymbol{m} / z(\mathbf{F T M S}+\mathbf{E S I}): \mathrm{M}+\mathrm{H}\left(\mathrm{C}_{20} \mathrm{H}_{21} \mathrm{O}_{6} \mathrm{~S}\right)$ requires 389.1053, found 389.1055. HPLC purity: $96.1 \%$

\subsubsection{Synthesis of 2-(3,4-dihydroxyphenyl)-3,5,7-trihydroxy-4H-chromene-4-thione (4)}

2-(3,4-Dimethoxyphenyl)-3,5,7-trimethoxy-4H-chromene-4-thione (3) (0.10 g, $0.257 \mathrm{mmol})$ was dissolved in anhydrous DCM (1 mL). $\mathrm{BBr}_{3}(0.35 \mathrm{~g}, 0.135 \mathrm{~mL}, 1.413 \mathrm{mmol}, 5.5$ eq., d=2.60 $\mathrm{g} / \mathrm{mL}$ ) was added and the reaction was stirred at $40{ }^{\circ} \mathrm{C}$ overnight. The reaction was cooled to room temperature and diluted with water $(2 \mathrm{~mL})$. The $\mathrm{pH}$ was adjusted to 6 with $5 \% \mathrm{Na}_{2} \mathrm{HPO}_{4}$ and the precipitated product was filtered to afford the crude product. The pure product, $2-(3,4-$ dimethoxyphenyl)-3,5,7-trihydroxy-4H-chromene-4-thione (4), was obtained as a bright red solid after purification by column chromatography [Solvent system: EtOAc (100\%)].

Yield: 55\%; m.p: $268-70{ }^{\circ} \mathrm{C}$ (decomposed); ${ }^{1} \mathbf{H}$ NMR: $\left(\mathrm{CDCl}_{3}, 400 \mathrm{MHz}\right) 6.34(1 \mathrm{H}, \mathrm{s}, \mathrm{H}-6)$, $6.54(1 \mathrm{H}, \mathrm{s}, \mathrm{H}-8), 6.92(1 \mathrm{H}, \mathrm{d}, J=8.5 \mathrm{~Hz}, \mathrm{H}-5$ ') $7.71(1 \mathrm{H}, \mathrm{d}, J=8.5 \mathrm{~Hz}, \mathrm{H}-6$ ') $7.76(1 \mathrm{H}, \mathrm{s}, \mathrm{H}-$ 2'), $8.66(1 \mathrm{H}, \mathrm{s}, \mathrm{OH}), 9.44(1 \mathrm{H}, \mathrm{s}, \mathrm{OH}), 9.91(1 \mathrm{H}, \mathrm{s}, \mathrm{OH}), 11.07(1 \mathrm{H}, \mathrm{s}, \mathrm{OH}), 13.06(1 \mathrm{H}, \mathrm{s}, \mathrm{OH})$; ${ }^{13}$ C NMR: $\left(\mathrm{CDCl}_{3}, 100 \mathrm{MHz}\right) \delta 93.8$ (C8), 100.4 (C6), 111.3 (C10), 115.7 (5'), 115.8 (C2'), 120.7(C6'), 121.6 (C1'), 142.4 (C3’), 142.7 (C4'), 145.3 (C9), 149.1 (C7), 152.5 (C2), 160.1 (C5), 163.5 (C3), $181.6(\mathbf{C}=\mathrm{S})$; IR $\boldsymbol{v}_{\max }\left[\mathbf{c m}^{-1}\right]: 1267$ (C=S, v, m), 1147(C-O, v, m), $3084(\mathrm{OH}$, 
w, b); $\boldsymbol{m} / \boldsymbol{z}$ (FTMS+ESI): $\mathrm{M}+\mathrm{H}\left(\mathrm{C}_{15} \mathrm{H}_{11} \mathrm{O}_{6} \mathrm{~S}\right)$ requires 319.0271, found 319.0266. HPLC purity: $99.4 \%$

\subsubsection{Synthesis of luteolin, methoxy luteolin and 4-thiomethoxy luteolin (9-12)}

\subsubsection{2-Acetyl-3, 5-dimethoxyphenyl 3, 4-dimethoxy benzoate (7)}

1-(2-Hydroxy-4, 6-dimethoxyphenyl) ethanone (5) (1 g, $5.09 \mathrm{mmol})$ was dissolved in pyridine $(20 \mathrm{~mL})$ and heated to $50{ }^{\circ} \mathrm{C}$. DBU (1\% v/v of pyridine) was added and the mixture was stirred at $50{ }^{\circ} \mathrm{C}$ for $30 \mathrm{~min} .3,4$-Dimethoxy benzoyl chloride (6) (1.53 g, $7.63 \mathrm{mmol}, 1.5$ eq.) was added slowly over $15 \mathrm{~min}$, the mixture was heated to $75^{\circ} \mathrm{C}$ and stirred for $1 \mathrm{~h}$. The reaction was cooled to room temperature, acidified to $\mathrm{pH} 5$ with $2 \mathrm{M} \mathrm{HCl}$ and extracted with EtOAc ( 2 x $20 \mathrm{~mL})$. The organic layers were combined, dried over anhydrous magnesium sulfate and concentrated in vacuo to yield the desiredproduct. The pure compound was obtained as a white solid after purification by column chromatography [Hexane: $\mathrm{CHCl}_{3}$ : EtOAc $\left.(3: 6: 1 \mathrm{v} / \mathrm{v} / \mathrm{v})\right]$.

Yield: $60 \%$; m.p: $151-53{ }^{\circ} \mathrm{C}$; ${ }^{1} \mathbf{H}$ NMR: $\left(\mathrm{CDCl}_{3}, 400 \mathrm{MHz}\right) \delta 2.47\left(3 \mathrm{H}, \mathrm{s},-\mathrm{CH}_{3}\right) 3.82(3 \mathrm{H}, \mathrm{s},-$ $\left.\mathrm{OCH}_{3}\right), 3.84\left(3 \mathrm{H}, \mathrm{s},-\mathrm{OCH}_{3}\right), 3.86\left(3 \mathrm{H}, \mathrm{s},-\mathrm{OCH}_{3}\right), 3.96\left(3 \mathrm{H}, \mathrm{s},-\mathrm{OCH}_{3}\right), 6.37(1 \mathrm{H}, \mathrm{s}, \mathrm{H}-4), 6.40$ $(1 \mathrm{H}, \mathrm{s}, \mathrm{H}-6), 6.91\left(1 \mathrm{H}, \mathrm{d}, J=8 \mathrm{~Hz}, \mathrm{H}-6\right.$ ') $7.61\left(1 \mathrm{H}, \mathrm{s}, \mathrm{H}-2\right.$ '), $7.80\left(1 \mathrm{H}, \mathrm{d}, J=7 \mathrm{~Hz}, \mathrm{H}-5\right.$ '); ${ }^{13} \mathbf{C}$ NMR: $\left(\mathrm{CDCl}_{3}, 100 \mathrm{MHz}\right) \delta 29.4\left(\mathrm{CH}_{3}\right), 56.0\left(-\mathrm{OCH}_{3}\right), 60.3\left(-\mathrm{OCH}_{3}\right), 109.7(\mathrm{C} 4), 111.1\left(\mathrm{C}{ }^{\prime}\right)$, 112.1 (C2'), 120.6 (C6), 124.3 (C5, C6'), 126.1 (C1'), 140.9 (C2), 143.5 (C3'), 153.5 (C3), $156.7\left(\mathrm{C}^{\prime}\right), 163.7(\mathbf{C O O}-\mathrm{Ar}), 195.5\left(\mathbf{C O C H}_{3}\right) ; \mathbf{I R} \boldsymbol{v}_{\max }\left[\mathbf{c m}^{-1}\right]: 1713(\mathrm{C}=\mathrm{O}, \mathrm{v}, \mathrm{m}), 1102(\mathrm{O}-$ $\mathrm{C}=\mathrm{O}, \mathrm{v}, \mathrm{m}), 1689(\mathrm{C}=\mathrm{O}, \mathrm{v}, \mathrm{m}), 1246\left(-\mathrm{OCH}_{3}, \mathrm{v}, \mathrm{s}\right) ; \boldsymbol{m} / \boldsymbol{z}(\mathbf{F T M S}+\mathbf{E S I}): \mathrm{M}+\mathrm{Na}\left(\mathrm{C}_{19} \mathrm{H}_{20} \mathrm{O}_{7} \mathrm{Na}\right)$ requires 383.1101 , found 383.1102 .

\subsubsection{1-(2-Hydroxy-4,6-dimethoxyphenyl)-3-phenyl propane-1, 3-dione (8)}

The 2-acetyl-3, 5-dimethoxyphenyl 3, 4-dimethoxy benzoate (7) (1.0 g, $2.7 \mathrm{mmol})$ was dissolved in pyridine $(15 \mathrm{~mL})$ and heated to $50{ }^{\circ} \mathrm{C}$ for $1 \mathrm{~h}$. Anhydrous potassium hydroxide [powdered] (0.32g, $5.4 \mathrm{mmol}, 2$ eq.) was added and the reaction was heated to $75{ }^{\circ} \mathrm{C}$. After $1 \mathrm{~h}$, 
the reaction mixture was cooled to room temperature, acidified to $\mathrm{pH} 5$ with $2 \mathrm{M} \mathrm{HCl}$ and extracted with EtOAc $(2 \times 5 \mathrm{~mL})$. The organic layers were combined, dried over anhydrous magnesium sulfate and concentrated in vacuo to yield the crude 1,3-diketone. The crude 1,3diketone was treated with glacial acetic acid to remove the pyridine and the yellow compound was used for the next step without purification.

Yield: $75 \%$; ${ }^{1} \mathbf{H}$ NMR: $\left(\mathrm{CDCl}_{3}, 400 \mathrm{MHz}\right)$ [The compound exists as a mixture of keto-enol tautomers] $\delta 3.78\left(2 \mathrm{H}, \mathrm{s},-\mathrm{CH}_{2}\right), 3.89-3.98\left(12 \mathrm{H}, 4 \mathrm{x}-\mathrm{OCH}_{3}\right), 5.98(1 \mathrm{H}, \mathrm{s}, \mathrm{H}-5), 5.99(1 \mathrm{H}, \mathrm{s}$, H-3), $6.02(1 \mathrm{H}, \mathrm{s},=\mathrm{CH}$ of enol form), $6.93(1 \mathrm{H}, \mathrm{d}, J=8.5 \mathrm{~Hz}, \mathrm{H}-6$ ') $7.27(1 \mathrm{H}, \mathrm{d}, J=7.0 \mathrm{~Hz}, \mathrm{H}-$ 5'), 7.44 (1H, s, H-2'), 13.44 (1H, s, OH), 13.72 (1H, s, OH of enol form).

\subsubsection{2-(3,4-Dimethoxyphenyl)-5,7-dimethoxy-4H-chomen-4-one (9)}

1-(2-Hydroxy-4,6-dimethoxyphenyl)-3-phenyl propane-1, 3-dione (8) (0.75g, $2.08 \mathrm{mmol})$ was dissolved in acetic acid $(6 \mathrm{~mL})$ and heated to $90{ }^{\circ} \mathrm{C}$ for $1 \mathrm{~h}$. Concentrated sulfuric acid (0.06 $\mathrm{mL}, 1 \% \mathrm{v} / \mathrm{v}$ of acetic acid) was added and the reaction was heated at $110{ }^{\circ} \mathrm{C}$ for $1 \mathrm{~h}$. The reaction mixture was cooled to room temperature, diluted with water $(10 \mathrm{~mL})$ and the aqueous layer was extracted with EtOAc $(2 \times 5 \mathrm{~mL})$. The organic layers were combined, dried over anhydrous magnesium sulfate and concentrated in vacuo to obtain the crude 2-(3,4dimethoxyphenyl)-5,7-dimethoxy-4H-chomen-4-one. The pure compound was obtained as a white solid after purification by column chromatography [Hexane: $\mathrm{CHCl}_{3}$ : EtOAc (3:6:1 v/v/v)].

Yield: 70\%; m.p: $192-93{ }^{\circ} \mathrm{C}$ (lit [37]-190-94 ${ }^{\circ} \mathrm{C}$ ); ${ }^{1} \mathbf{H}$ NMR: (DMSO-d6, $\left.400 \mathrm{MHz}\right) \delta 3.82(3 \mathrm{H}$, s, $\left.-\mathrm{OCH}_{3}\right) 3.83\left(3 \mathrm{H}, \mathrm{s},-\mathrm{OCH}_{3}\right), 3.87\left(3 \mathrm{H}, \mathrm{s},-\mathrm{OCH}_{3}\right), 3.89\left(3 \mathrm{H}, \mathrm{s},-\mathrm{OCH} \mathbf{H}_{3}\right), 6.49(1 \mathrm{H}, \mathrm{s}, \mathrm{H}-3)$, 6.76 (1H, s, H-6), 6.86 (1H, s, H-8), 7.01 (1H, d, J= 8.5 Hz, H-6’), 7.52 (1H, s, H-2'), 7.63 (1H, d, $J=8.0 \mathrm{~Hz}, \mathrm{H}-5$ '); ${ }^{13} \mathbf{C}$ NMR: (DMSO-d6, $\left.100 \mathrm{MHz}\right) \delta 55.9\left(-\mathrm{OCH}_{3}\right), 93.4(\mathrm{C} 8), 96.3(\mathrm{C} 6)$, 107.0 (C3'), 107.9 (C10), 108.7 (C6’), 111.5 (C3’), 119.2 (C2'), 122.9 (C1'), 149.1 (C4'), 151.5 (C5'), 159.0 (C9), 159.3 (C5), 160.4 (C2), 163.9 (C7), 175.7 (C=O); IR $\boldsymbol{v}_{\max }\left[\mathbf{c m}^{-1}\right]$ : 1644 
$(\mathrm{C}=\mathrm{O}, \mathrm{v}, \mathrm{m}), 1252\left(-\mathrm{OCH}_{3}, \mathrm{v}, \mathrm{m}\right) 1138(\mathrm{C}-\mathrm{O}, \mathrm{v}, \mathrm{m}) ; \boldsymbol{m} / \mathbf{z}(\mathbf{F T M S}+\mathbf{E S I}): \mathrm{M}+\mathrm{H}\left(\mathrm{C}_{19} \mathrm{H}_{19} \mathrm{O}_{6}\right)$ requires 343.1176, found 343.1176. HPLC purity: $99.5 \%$

\subsubsection{2-(3,4-Dihydroxyphenyl)-5,7-dihydroxy-4H-chomen-4-one (10)}

2-(3,4-Dimethoxyphenyl)-5,7-dimethoxy-4H-chomen-4-one (9) (100 mg, $0.292 \mathrm{mmol}$ ) was dissolved in anhydrous DCM (1 mL). $\mathrm{BBr}_{3}(329.32 \mathrm{mg}, 0.126 \mathrm{~mL}, 1.314 \mathrm{mmol}, 4.5$ eq., $\mathrm{d}=2.60$ $\mathrm{g} / \mathrm{mL}$ ) was added and stirred at $40{ }^{\circ} \mathrm{C}$ overnight. The reaction was cooled to room temperature and diluted with water $(2 \mathrm{~mL})$. The $\mathrm{pH}$ was adjusted to 6 with $5 \% \mathrm{Na}_{2} \mathrm{HPO}_{4}$ and the aqueous layer was extracted with n-butanol $(2 \times 5 \mathrm{~mL})$. The organic layer was washed with brine, dried over anhydrous magnesium sulfate and concentrated in vacuo. The crude product was purified by column chromatography [Solvent system: EtOAc $(100 \%)$ ] to afford 2-(3, 4dihydroxyphenyl)-5,7-dihydroxy-4H-chomen-4-one (10) as a pale yellow solid.

Yield: 59\%; m.p:328-29 ${ }^{\circ} \mathrm{C}$ (lit [38]-326-28 ${ }^{\circ} \mathrm{C}$ ); ${ }^{1} \mathbf{H}$ NMR: (DMSO-d6, $\left.400 \mathrm{MHz}\right) \delta 6.25(1 \mathrm{H}$, s, H-3), 6.50 (1H, s, H-6), 6.72 (1H, s, H-8), 6.95 (1H, d, J= 8.0 Hz, H-6’), 7.45 (1H, s, H-2'), $7.46(1 \mathrm{H}, \mathrm{d}, J=8.0 \mathrm{~Hz}, \mathrm{H}-5$ '), $9.48(1 \mathrm{H}, \mathrm{s}, \mathrm{OH}), 9.98(1 \mathrm{H}, \mathrm{s}, \mathrm{OH}), 10.90(1 \mathrm{H}, \mathrm{s}, \mathrm{OH}), 13.02(1 \mathrm{H}$, s, OH) ; ${ }^{13}$ C NMR: (DMSO-d6, 100 MHz) $\delta 93.7$ (C8), 98.8 (C6), 102.6 (C3), 103.6 (C10), 113.2 (C2'), 115.9 (C5'), 118.9 (C6’), 121.4 (C1'), 145.6 (C3'), 149.6 (C4'), 157.2 (C9), 161.4 (C5), $163.8(\mathrm{C} 2),(164.0, \mathrm{C} 7), 181.6(\mathbf{C}=\mathrm{O}) ; \mathbf{I R} \boldsymbol{v}_{\max }\left[\mathbf{c m}^{-1}\right]: 1600(\mathrm{C}=\mathrm{O}, \mathrm{v}, \mathrm{s}), 1160(\mathrm{C}-\mathrm{O}, \mathrm{v}, \mathrm{m})$, $3236(\mathrm{OH}, \mathrm{w}, \mathrm{b})$; IR $\boldsymbol{v}_{\max }\left[\mathbf{c m}^{-1}\right]: 1600(\mathrm{C}=\mathrm{O}, \mathrm{v}, \mathrm{s}), 1160(\mathrm{C}-\mathrm{O}, \mathrm{v}, \mathrm{m}), 3236(\mathrm{OH}, \mathrm{w}, \mathrm{b}) ; \mathbf{m} / \mathbf{z}$ (FTMS+ESI): $\mathrm{M}+\mathrm{H}\left(\mathrm{C}_{15} \mathrm{H}_{11} \mathrm{O}_{4}\right)$ requires 287.0550, found 287.0554. HPLC purity: $99.4 \%$

\subsubsection{Synthesis of 2-(3,4-dimethoxyphenyl)-5,7-dimethoxy-4H-chromene-4-thione (11)}

2-(3,4-Dimethoxyphenyl)-5,7-dimethoxy-4H-chomen-4-one (9) (0.25 g, $0.73 \mathrm{mmol})$ was dissolved in anhydrous toluene $(1 \mathrm{~mL})$, Lawesson's reagent $(0.30 \mathrm{~g}, 0.73 \mathrm{mmol}, 1 \mathrm{eq}$.$) was$ added and the reaction was heated to $110{ }^{\circ} \mathrm{C}$ for $4 \mathrm{~h}$. The reaction mixture was cooled to room temperature and concentrated in vacuo. The residue was purified by column chromatography 
[Solvent system: Hexane: $\mathrm{CHCl}_{3}$ : EtOAc $\left.(3: 6: 1 \mathrm{v} / \mathrm{v} / \mathrm{v})\right]$ to obtain the pure compound as a green solid.

Yield: 61\%; m.p: $204-5{ }^{\circ} \mathrm{C}$ (lit [36]-203 ${ }^{\circ} \mathrm{C}$ ); ${ }^{\mathbf{1}} \mathbf{H}$ NMR: (DMSO-d6, $\left.400 \mathrm{MHz}\right) \delta 3.82(3 \mathrm{H}, \mathrm{s},-$ $\left.\mathrm{OCH}_{3}\right) 3.86\left(3 \mathrm{H}, \mathrm{s},-\mathrm{OCH}_{3}\right), 3.90\left(3 \mathrm{H}, \mathrm{s},-\mathrm{OCH}_{3}\right), 3.94\left(3 \mathrm{H}, \mathrm{s},-\mathrm{OCH}_{3}\right), 6.58(1 \mathrm{H}, \mathrm{s}, \mathrm{H}-2$ '), 6.94 (1H, s, H-8), $7.13(1 \mathrm{H}, \mathrm{d}, J=8.0 \mathrm{~Hz}, \mathrm{H}-5$ ') $7.53(1 \mathrm{H}, \mathrm{s}, \mathrm{H}-3), 7.55(1 \mathrm{H}, \mathrm{s}, \mathrm{H}-6), 7.69(1 \mathrm{H}, \mathrm{d}, J=$ 8.0 Hz, H-6'); ${ }^{13}$ C NMR: (DMSO-d6, $\left.100 \mathrm{MHz}\right) \delta 53.6\left(-\mathrm{OCH}_{3}\right), 53.7\left(-\mathrm{OCH}_{3}\right), 53.8\left(-\mathrm{OCH}_{3}\right)$, $54.0\left(-\mathrm{OCH}_{3}\right), 91.2(\mathrm{C} 8), 94.8(\mathrm{C} 6), 107.0\left(\mathrm{C}^{\prime}\right), 109.8\left(\mathrm{C}^{\prime}\right), 114.3(\mathrm{C} 10), 117.8(\mathrm{C} 3), 118.1$ (C6’), 120.2 (C1'), 147.0 (C4'), 147.2 (C3’), 149.7 (C2), 152.9 (C9), 158.7 (C7), 161.4 (C5), $196.7(\mathbf{C}=\mathrm{S}) ; \mathbf{I R} \boldsymbol{v}_{\max }\left[\mathbf{c m}^{-1}\right]: 1316(\mathrm{C}=\mathrm{S}, \boldsymbol{v}, \mathrm{m}), 1254\left(-\mathrm{OCH}_{3}, v, \mathrm{~m}\right) 1140(\mathrm{C}-\mathrm{O}, \mathrm{v}, \mathrm{m}) ; \boldsymbol{m} / \boldsymbol{z}$ (FTMS+ESI): $\mathrm{M}+\mathrm{H}\left(\mathrm{C}_{19} \mathrm{H}_{19} \mathrm{O}_{5} \mathrm{~S}\right)$ requires 359.0948, found 359.0948. HPLC purity: $95.7 \%$

\subsubsection{Synthesis of 2-(3, 4-dihydroxyphenyl)-5, 7-dihydroxy-4H-chromene-4-thione (12)}

2-(3,4-Dimethoxyphenyl)-5,7-dimethoxy-4H-chromene-4-thione (11) (0.15 g, $0.418 \mathrm{mmol})$ was dissolved in anhydrous DCM (1 mL). $\mathrm{BBr}_{3}(0.47 \mathrm{~g}, 0.181 \mathrm{~mL}, 1.86 \mathrm{mmol}, 4.45 \mathrm{eq} ., \mathrm{d}=2.60$ $\mathrm{g} / \mathrm{mL}$ ) was added and the reaction was stirred at $40{ }^{\circ} \mathrm{C}$ overnight. The reaction was cooled to room temperature and diluted with water $(2 \mathrm{~mL})$. The $\mathrm{pH}$ was adjusted to 6 with $5 \% \mathrm{Na}_{2} \mathrm{HPO}_{4}$ and the precipitated product was filtered and purified by column chromatography [Solvent system: EtOAc (100\%)] to obtain the pure compound as a brown solid.

Yield: 55\%; m.p: $269-70{ }^{\circ} \mathrm{C} ;{ }^{\mathbf{1}} \mathbf{H}$ NMR: (DMSO-d6, $\left.400 \mathrm{MHz}\right) \delta 6.29(1 \mathrm{H}, \mathrm{s}, \mathrm{H}-2$ '), $6.51(1 \mathrm{H}$, s, H-8), 6.89 (1H, d, J= 8.0 Hz, H-5'), $7.31(1 \mathrm{H}, \mathrm{s}, \mathrm{H}-3), 7.43(1 \mathrm{H}, \mathrm{s}, \mathrm{H}-6), 7.49$ (1H, d, J= 8.0 Hz, H-6'), 9.80 (1H, s, OH), $10.12(1 \mathrm{H}, \mathrm{s}, \mathrm{OH}), 11.20(1 \mathrm{H}, \mathrm{s}, \mathrm{OH}), 13.67(1 \mathrm{H}, \mathrm{s}, \mathrm{OH}) ;{ }^{13} \mathbf{C}$ NMR: (DMSO-d6, 100 MHz) $\delta 94.4$ (C8), 100.5 (C6), 111.6 (C10), 113.5 (C2'), 115.7 (C5'), 116.2 (C3), 119.7 (C1'), 120.1 (C6’), 145.9 (C3'), 150.3 (C4'), 153.9 (C2), 155.1 (C9), 161.7 (C7), 164.0 (C5), $194.5(\mathbf{C}=\mathrm{S})$; IR $\boldsymbol{v}_{\max }\left[\mathbf{c m}^{-1}\right]: 1444(\mathrm{C}=\mathrm{S}, \mathrm{v}, \mathrm{m}), 1146(\mathrm{C}-\mathrm{O}, \mathrm{v}, \mathrm{m}), 3293(\mathrm{OH}$, 
$\mathrm{w}, \mathrm{b}) ; \boldsymbol{m} / \boldsymbol{z}$ (FTMS+ESI): $\mathrm{M}+\mathrm{H}\left(\mathrm{C}_{15} \mathrm{H}_{11} \mathrm{O}_{5} \mathrm{~S}\right)$ requires 303.0322, found 303.0326. HPLC purity: $99.3 \%$

\subsubsection{In vitro cell migration (Scratch assay)}

HUVECs were seeded in 12-well plates at $3 \times 10^{4}$ cells/well and cultured for $48 \mathrm{~h}$. After $48 \mathrm{~h}$, they were serum-starved $(0.1 \%$ serum $)$ for $24 \mathrm{~h}$ to inactivate the cell proliferation. A scratch was performed on the cell monolayers using a $100 \mu \mathrm{L}$ pipette tip. Cells were then washed twice with PBS and then treated with medium containing VEGF $(10 \mathrm{ng} / \mathrm{mL})$ and either quercetin, luteolin, or one of the synthesised derivatives (at $10 \mu \mathrm{M}$ or $1 \mu \mathrm{M}$ ). Images of the scratches were taken immediately after performing the scratch $(\mathrm{t}=0 \mathrm{~h})$ and at $12 \mathrm{~h}(\mathrm{t}=12 \mathrm{~h})$. The area not covered by the cells was quantified using ImageJ software. Data were normalized to the presence or absence of VEGF (VEGF and VEGF-free medium were set at $100 \%$ and $0 \%$, respectively).

\subsubsection{Cell viability (MTT assay)}

MCF-7 and MCF-7/DX cells were seeded at a density of $4 \times 10^{4}$ into 96 well plates and incubated to allow the attachment for $24 \mathrm{~h}$. After $24 \mathrm{~h}$, the cells were treated with either quercetin, luteolin or one of the synthesised derivatives at range of concentrations ( 0 to $250 \mu \mathrm{M})$ for $67 \mathrm{~h}$. After $67 \mathrm{~h}, 20 \mu \mathrm{L}$ of MTT $(5 \mathrm{mg} / \mathrm{mL})$ solution in PBS was added to each well and the cells were incubated for $5 \mathrm{~h}$. The purple crystals formed were dissolved in $100 \mu \mathrm{L}$ of DMSO and the plates were read at $570 \mathrm{~nm}$ using a SPECTRA max UV spectrometer (Bio-Rad). The data represented are the mean of the three individual experiments.

\subsubsection{Western blotting}

HUVECs were cultured in 6-well plates at $1 \times 10^{5}$ cells/well and cultured for $48 \mathrm{~h}$. After $48 \mathrm{~h}$, they were serum-starved $(0.1 \%$ serum $)$ for $24 \mathrm{~h}$ to inhibit cell proliferation. Cells were then 
pretreated with or without quercetin, luteolin or one of their derivatives for $1 \mathrm{~h}$, followed by stimulation with $10 \mathrm{ng} / \mathrm{mL}$ of VEGF for $15 \mathrm{~min}$ (for VEGFR2 activation). Cells were washed twice with ice-cold PBS and lysed using $100 \mu \mathrm{L}$ radioimmunoprecipitation assay (RIPA) lysis buffer with $1 \%$ protease inhibitor and phosphatase inhibitor. The amount of protein present in the cell lysate was assessed using the DC (Bio-Rad) protein assay developed from Lowry's protocol for protein assessment. Proteins $(15 \mu \mathrm{g})$ were separated by SDS-PAGE and then transferred to PVDF membranes. Membranes were blocked with 3\% fat-free dry milk in PBT buffer and then probed for $\mathrm{P}^{\text {Tyr-1175}}$-VEGFR2 (1:1000) or total VEGFR2 $(1: 1000)$ and actin dilution. Protein bands were detected by incubating with horseradish peroxidase-conjugated antibodies $(1: 10,000)$ and visualised with enhanced chemiluminescence reagent using ImageQuant LAS 4000 (GE Healthcare). Gelbands were standardised to total protein loading relative to actin by using a Gel-Pro analyzer6.0 software as previously described [39].

\subsubsection{Molecular docking}

Docking validation-To validate the accuracy of the docking procedure to be used, the original ligands were extracted from the coordinate files (taken from the Protein Data Bank PDB), and then docked again into the corresponding crystal structure of the proteins, using the automated docking procedure in the program Surflex-Dock (SFXC) [40], as provided by SYBYL-X2.1. The resulting ligand conformation from the docking procedure was compared with the ligand conformation as found in the actual crystal structure of the complex. Comparative structural orientation of the ligand was calculated as the root mean square deviation (RSMD) between the docked ligand and the ligand as found in the crystal structure, using the programme LSQKAB, as provided in the CCP4 [41] suite. If the root mean square deviation (RMSD) value between the real and the best-scored conformations is equal to or less than $2.0 \AA$ (representing the grid spacing used for the docking procedure), then the docking process was considered successful [42]. 
Docking procedure- Docking studies were performed using the program Surflex-Dock (SFXC) as provided by Sybyl-X 2.1. The X-ray crystallographic structures of human VEGFR2 receptor complexed with 4-amino-furo[2,3-d]pyrimidine (PDB code1YWN, $1.71 \AA$ A resolution) [43] and human VEGF protein complexed with receptor blocking peptide (PDB code1VPP, $1.90 \AA$ resolution) [44] were retrieved from the Protein Data Bank. The protein structures were prepared for docking using the Biopolymer Structure Preparation Tool with the implemented default settings provided in the SYBYL programme suite. Hydrogens were added to the protein structures in idealised geometries and an overall energy minimisation of each protein was performed using the MMFF94 force field, employing a conjugate gradient algorithm [45] with a convergence criterion of $0.5 \mathrm{kcal} / \mathrm{mol} \mathrm{A}^{-1}$ and up to 5000 iterations. Finally, before the docking run, all water molecules were removed and the ligand 4-amino-furo[2,3-d]pyrimidine was extracted from the coordinate file of the VEGFR2 receptor (1YWN). The protomol, representing the ligand binding groove, was generated using a ligand directed method for VEGFR2, which allows the docking of ligands into predefined sites, as defined by occupancy of any cocrystallised ligand at the site of interest. In the case of VEGF, as the crystal structure was not bound to any ligand, the protomol was generated using the automatic docking procedure.

The Surflex-X docking algorithm docks a given ligand to a receptor using a flexible ligand and a semi-flexible receptor; in this case the peptides were allowed to be fully flexible while the receptor was semi-flexible. This allows for optimisation of potentially favourable molecular interactions, such as those defined by hydrogen bond and van der Waal forces. The docking results yield a docking score, which takes into consideration entropic, polar, hydrophobic, repulsive and desolvation factors. The docking scores were expressed in $-\log 10\left(\mathrm{~K}_{\mathrm{d}}\right)$ units to represent binding affinities, where $\mathrm{K}_{\mathrm{d}}$ is the dissociation constant. The free energy of binding of the ligand to the protein was extrapolated from equation (1). 
The docking results were visualised using the program PyMOL $[46,47]$ and the molecular interactions of the docked ligands were analysed by the programme CONTACTS, as provided in the CCP4 suite of programs [41]'[48],[49]. Potential hydrogen bonds were assigned if the distance between two electronegative atoms was less than $3.3 \AA$, whereas any separation greater than $3.3 \AA$, but less than $4.5 \AA$, was considered a van der Waal interaction.

\subsubsection{DSC (Membrane perturbation effect)}

DSC measurements were performed using the differential scanning calorimeter nano-DSC (TA instruments, UK). The samples were degassed before being loaded into the reference and sample cells. A scan rate of $1.5^{\circ} \mathrm{C} / \mathrm{min}$ over the temperature range $20-70{ }^{\circ} \mathrm{C}$ was employed. Data were analysed using nano analyser software provided by TA instrument.

Liposome preparation: Model membranes [multilamellar vesicles (MLVs)] were prepared using dipalmitoylphosphatidylcholine (DPPC) lipid. DPPC was dissolved in chloroform and the solvent was evaporated under vacuum to obtain a lipid film. The resulted lipid film was hydrated with an appropriate volume of $20 \mathrm{mM}$ sodium phosphate buffer at $\mathrm{pH} 7.0$ at room temperature, followed by 3-4 freeze-thawing cycles. For DSC experiments, samples were prepared by mixing the lipid and drug solutions to obtain $0.2 \mathrm{mg} / \mathrm{mL}$ of lipid and 10 or $100 \mu \mathrm{M}$ of compound-1 to 3 and $\mathbf{9}$ to $\mathbf{1 1}$.

\section{ASSOCIATED CONTENT}

Supporting Information. ${ }^{1} \mathrm{H}$ NMR spectra of compounds 2-4 and 9-12 and DSC profiles of compounds 1-3 and 9-12 are provided here. This material is available online.

\section{AUTHOR INFORMATION}

\section{Corresponding Authors}


*Helen. M. I. Osborn.

Tel: $+44(0) 118$ 378-7338,

E-mail address: h.m.i.osborn@reading.ac.uk.

*Francesca Greco

Tel: +44 (0) $118378-8244$

E-mail address: f.greco@reading.ac.uk

\section{Present Addresses}

Reading School of Pharmacy, University of Reading, Whiteknights, Reading, UK, RG6 6AD.

\section{ACKNOWLEDGEMENT}

Financial support from the Felix Trust and funding from the Royal Society (grant award reference RG110203) are gratefully acknowledged. We thank Amit Kumar Rajora and Anju Paudyal for their help with Western blotting and Olga Florek for her help with DSC experiment. We also thank the University of Reading for the provision of the Chemical Analysis Facility.

\section{ABBREVIATIONS}

VEGF-Vascular endothelial growth factor; PDB-Protein data bank; SDS-PAGE- Sodium dodecyl sulphate-Polyacrylamide gel electrophoresis; DSC-Differential scanning calorimetry; PVDF-Polyvinylidene fluoride, MMFF94-Merck molecular force field; MTT-3-(4,5dimethylthiazol-2-yl)-2,5-diphenyltetrazolium bromide; NMR-Nuclear magnetic resonance; IRInfrared; FTMS-Fourier transform mass spectroscopy; ESI-Electron spray ionisation.

\section{REFERENCES}

[1] P. Carmeliet, R.K. Jain, Angiogenesis in cancer and other diseases., Nature. 407 (2000) 249-257. doi:10.1038/35025220.

[2] D. Hanahan, J. Folkman, Patterns and emerging mechanisms of the angiogenic switch during tumorigenesis, Cell. 86 (1996) 353-364. doi:10.1016/S0092-8674(00)80108-7. 
[3] D. Hanahan, The Hallmarks of Cancer, Cell. 100 (2000) 57-70. doi:10.1016/S00928674(00)81683-9.

[4] D. Hanahan, R.A. Weinberg, Hallmarks of cancer: The next generation, Cell. 144 (2011) 646-674. doi:10.1016/j.cell.2011.02.013.

[5] N. Ferrara, R.S. Kerbel, Angiogenesis as a therapeutic target., Nature. 438 (2005) 967974. doi:10.1038/nature04483.

[6] D. Ravishankar, A.K. Rajora, F. Greco, H.M.I. Osborn, Flavonoids as prospective compounds for anti-cancer therapy., Int. J. Biochem. Cell Biol. 45 (2013) 2821-31. doi:10.1016/j.biocel.2013.10.004.

[7] A.M. Senderowicz, Flavopiridol: the first cyclin-dependent kinase inhibitor in human clinical trials., Invest. New Drugs. 17 (1999) 313-320.

[8] S. Burdette-Radoux, R.G. Tozer, R.C. Lohmann, I. Quirt, D.S. Ernst, W. Walsh, et al., Phase II trial of flavopiridol, a cyclin dependent kinase inhibitor, in untreated metastatic malignant melanoma, Invest. New Drugs. 22 (2004) 315-322.

doi:10.1023/B:DRUG.0000026258.02846.1c.

[9] J.A. Jones, A.S. Rupert, M. Poi, M.A. Phelps, L. Andritsos, R. Baiocchi, et al., Flavopiridol can be safely administered using a pharmacologically derived schedule and demonstrates activity in relapsed and refractory non-Hodgkin's lymphoma, Am. J. Hematol. 89 (2014) 19-24. doi:10.1002/ajh.23568.

[10] C. Loguercio, D. Festi, Silybin and the liver: from basic research to clinical practice., World J. Gastroenterol. 17 (2011) 2288-2301. doi:10.3748/wjg.v17.i18.2288.

[11] D. Ferry, A. Smith, J. Malkhandi, Phase I clinical trial of the flavonoid quercetin: pharmacokinetics and evidence for in vivo tyrosine kinase inhibition., Clin. Cancer Res. (1996) 659-668. http://clincancerres.aacrjournals.org/content/2/4/659.short (accessed October 7, 2014).

[12] P.J. Mulholland, D.R. Ferry, D. Anderson, S.A. Hussain, A.M. Young, J.E. Cook, et al., Pre-clinical and clinical study of QC12, a water-soluble, pro-drug of quercetin, Ann. Oncol. 12 (2001) 245-248. doi:10.1023/A:1008372017097.

[13] P. Pratheeshkumar, A. Budhraja, Y.O. Son, X. Wang, Z. Zhang, S. Ding, et al., Quercetin Inhibits Angiogenesis Mediated Human Prostate Tumor Growth by Targeting VEGFR- 2 Regulated AKT/mTOR/P70S6K Signaling Pathways, PLoS One. 7 (2012). doi:10.1371/journal.pone.0047516.

[14] P. Pratheeshkumar, Y.-O. Son, A. Budhraja, X. Wang, S. Ding, L. Wang, et al., Luteolin inhibits human prostate tumor growth by suppressing vascular endothelial growth factor receptor 2-mediated angiogenesis., PLoS One. 7 (2012) e52279. doi:10.1371/journal.pone.0052279.

[15] N. Ferrara, H.-P. Gerber, J. LeCouter, The biology of VEGF and its receptors., Nat. Med. 9 (2003) 669-676. doi:10.1038/nm0603-669. 
[16] J.J. Wedge SR, VEGF receptor tyrosine kinase inhibitors for the treatment of cancer, in: Tumor Angiogenes. Basic Mech. Cancer Ther., N, ed., Springer, New York:, 2008: pp. 395-423.

[17] S.A. Eccles, W. Court, L. Patterson, S. Sanderson, In vitro assays for endothelial cell functions related to angiogenesis: proliferation, motility, tubular differentiation, and proteolysis., Methods Mol. Biol. 467 (2009) 159-181. doi:10.1007/978-1-59745-2410_9.

[18] C.A. Staton, M.W.R. Reed, N.J. Brown, A critical analysis of current in vitro and in vivo angiogenesis assays, Int. J. Exp. Pathol. 90 (2009) 195-221. doi:10.1111/j.13652613.2008.00633.x.

[19] L. Lamalice, F. Le Boeuf, J. Huot, Endothelial cell migration during angiogenesis, Circ. Res. 100 (2007) 782-794. doi:10.1161/01.RES.0000259593.07661.1e.

[20] C.-C. Liang, A.Y. Park, J.-L. Guan, In vitro scratch assay: a convenient and inexpensive method for analysis of cell migration in vitro., Nat. Protoc. 2 (2007) 329-333. doi:10.1038/nprot.2007.30.

[21] M. Shibuya, Vegf-vegfr signals in health and disease, Biomol. Ther. 22 (2014) 1-9. doi:10.4062/biomolther.2013.113.

[22] X. Li, L. Claesson-Welsh, M. Shibuya, VEGF receptor signal transduction., Methods Enzymol. 443 (2008) 261-284. doi:10.1016/S0076-6879(08)02013-2.

[23] H.I. Ingólfsson, P. Thakur, K.F. Herold, E.A. Hobart, N.B. Ramsey, X. Periole, et al., Phytochemicals perturb membranes and promiscuously alter protein function., ACS Chem. Biol. 9 (2014) 1788-98. doi:10.1021/cb500086e.

[24] R.A. Videira, M.C. Antunes-Madeira, V.M.C. Madeira, Perturbations induced by $\alpha-$ and $\beta$-endosulfan in lipid membranes: A DSC and fluorescence polarization study, Biochim. Biophys. Acta - Biomembr. 1419 (1999) 151-163. doi:10.1016/S0005-2736(99)00060-7.

[25] R.L. Biltonen, D. Lichtenberg, The use of differential scanning calorimetry as a tool to characterize liposome preparations, Chem. Phys. Lipids. 64 (1993) 129-142. doi:10.1016/0009-3084(93)90062-8.

[26] D. Bilge, I. Sahin, N. Kazanci, F. Severcan, Interactions of tamoxifen with distearoyl phosphatidylcholine multilamellar vesicles: FTIR and DSC studies, Spectrochim. Acta Part A Mol. Biomol. Spectrosc. 130 (2014) 250-256. doi:http://dx.doi.org/10.1016/j.saa.2014.04.027.

[27] B. Pawlikowska-Pawlęga, H. Dziubińska, E. Król, K. Trȩbacz, A. Jarosz-Wilkołazka, R. Paduch, et al., Characteristics of quercetin interactions with liposomal and vacuolar membranes, Biochim. Biophys. Acta - Biomembr. 1838 (2014) 254-265. doi:10.1016/j.bbamem.2013.08.014.

[28] B. Pawlikowska-Pawlega, W. Ignacy Gruszecki, L. Misiak, R. Paduch, T. Piersiak, B. Zarzyka, et al., Modification of membranes by quercetin, a naturally occurring flavonoid, 
via its incorporation in the polar head group, Biochim. Biophys. Acta - Biomembr. 1768 (2007) 2195-2204. doi:10.1016/j.bbamem.2007.05.027.

[29] R. Sinha, M. Gadhwal, U. Joshi, S. Srivastava, G. Govil, Modifying effect of quercetin on model biomembranes: Studied by molecular dynamic simulation, DSC and NMR, Int J Curr Pharm Res. 4 (2012) 70-79.

http://scholar.google.com/scholar?hl=en\&btnG=Search\&q=intitle:Modifying+effect+of+ quercetin+on+model+biomembranes-

studied+by+molecular+dynamic+simulation,+DSC+and+NMR\#0 (accessed December 30, 2014).

[30] T. Mosmann, Rapid colorimetric assay for cellular growth and survival: application to proliferation and cytotoxicity assays., J. Immunol. Methods. 65 (1983) 55-63. doi:10.1016/0022-1759(83)90303-4.

[31] S.R. Wedge, J. Kendrew, L.F. Hennequin, P.J. Valentine, S.T. Barry, S.R. Brave, et al., AZD2171: A highly potent, orally bioavailable, vascular endothelial growth factor receptor-2 tyrosine kinase inhibitor for the treatment of cancer, Cancer Res. 65 (2005) 4389-4400. doi:10.1158/0008-5472.CAN-04-4409.

[32] A. Bagri, L. Berry, B. Gunter, M. Singh, I. Kasman, L.A. Damico, et al., Effects of antiVEGF treatment duration on tumor growth, tumor regrowth, and treatment efficacy, Clin. Cancer Res. 16 (2010) 3887-3900. doi:10.1158/1078-0432.CCR-09-3100.

[33] M.R. Mancuso, R. Davis, S.M. Norberg, S. O’Brien, B. Sennino, T. Nakahara, et al., Rapid vascular regrowth in tumors after reversal of VEGF inhibition, J. Clin. Invest. 116 (2006) 2610-2621. doi:10.1172/JCI24612.

[34] J. Ma, D.J. Waxman, Combination of antiangiogenesis with chemotherapy for more effective cancer treatment., Mol. Cancer Ther. 7 (2008) 3670-3684. doi:10.1158/15357163.MCT-08-0715.

[35] J. Yuan, I.L.K. Wong, T. Jiang, S.W. Wang, T. Liu, B. Jin Wen, et al., Synthesis of methylated quercetin derivatives and their reversal activities on P-gp- and BCRPmediated multidrug resistance tumour cells, Eur. J. Med. Chem. 54 (2012) 413-422. doi:10.1016/j.ejmech.2012.05.026.

[36] Ernst Bayer and Bruno Krämer, Synthese von Quercetylenderivaten, Chem. Ber. 97 (1964) 1057-1068.

[37] M. Barontini, R. Bernini, F. Crisante, G. Fabrizi, Selective and efficient oxidative modifications of flavonoids with 2-iodoxybenzoic acid (IBX), Tetrahedron. 66 (2010) 6047-6053. doi:10.1016/j.tet.2010.06.014.

[38] R.N. Yadava, U.K. Vishwakarma, New biologically active allelochemical from seeds of Cassia absus Linn ., Indian J. Chem., Sect B. 52 (2013) 953-957.

[39] S.Y. Boateng, A.M. Seymour, N.S. Bhutta, M.J. Dunn, M.H. Yacoub, K.R. Boheler, Subantihypertensive doses of ramipril normalize sarcoplasmic reticulum calcium ATPase 
expression and function following cardiac hypertrophy in rats., J. Mol. Cell. Cardiol. 30 (1998) 2683-2694. doi:10.1006/jmcc.1998.0830.

[40] A.N. Jain, Surflex : Fully Automatic Flexible Molecular Docking Using a Molecular Similarity-Based Search Engine Surflex : Fully Automatic Flexible Molecular Docking Using a Molecular, J. Med. Chem. 46 (2003) 499 -511. doi:10.1021/jm020406h.

[41] Collaborative Computational Project, Number 4, "The CCP4 suite: programs for protein crystallography,” Acta Crystallogr., Sect. D Biol. Crystallogr. D50 (1994) 760-763.

[42] R. Wang, Y. Lu, S. Wang, Comparative evaluation of 11 scoring functions for molecular docking, J. Med. Chem. 46 (2003) 2287-2303. doi:10.1021/jm0203783.

[43] Y. Miyazaki, S. Matsunaga, J. Tang, Y. Maeda, M. Nakano, R.J. Philippe, et al., Novel 4amino-furo[2,3-d]pyrimidines as Tie-2 and VEGFR2 dual inhibitors, Bioorganic Med. Chem. Lett. 15 (2005) 2203-2207. doi:10.1016/j.bmcl.2005.03.034.

[44] C. Wiesmann, H.W. Christinger, A.G. Cochran, B.C. Cunningham, W.J. Fairbrother, C.J. Keenan, et al., Crystal structure of the complex between VEGF and a receptor-blocking peptide, Biochemistry. 37 (1998) 17765-17772. doi:10.1021/bi9819327.

[45] M.J.D. Powell, Restart procedures for the conjugate gradient method, Math. Program. 12 (1977) 241-254. doi:10.1007/BF01593790.

[46] W. DeLano, Pymol: An open-source molecular graphics tool, CCP4 Newsl. Protein Crystallogr. (2002). http://www.ccp4.ac.uk/newsletters/newsletter40.pdf\#page=44.

[47] L. Grell, C. Parkin, L. Slatest, P.A. Craig, EZ-Viz, a tool for simplifying molecular viewing in PyMOL, Biochem. Mol. Biol. Educ. 34 (2006) 402-407. doi:10.1002/bmb.2006.494034062672.

[48] K. Cowtan, P. Emsley, K.S. Wilson, From crystal to structure with CCP4, Acta Crystallogr. Sect. D Biol. Crystallogr. 67 (2011) 233-234. doi:10.1107/S0907444911007578.

[49] M.D. Winn, C.C. Ballard, K.D. Cowtan, E.J. Dodson, P. Emsley, P.R. Evans, et al., Overview of the CCP4 suite and current developments, Acta Crystallogr. Sect. D Biol. Crystallogr. 67 (2011) 235-242. doi:10.1107/S0907444910045749. 


\section{List of captions of schemes, figures and tables.}

\section{Scheme 1- Synthesis of methoxy and 4-thiocarbonyl analogues of quercetin}

\section{Scheme 2- Synthesis of luteolin and its methoxy and 4-thiocarbonyl analogues}

Figure 10. The quercetin and luteolin derivatives synthesised and evaluated in this study.

Figure 11. Effects of quercetin and its derivatives on VEGF-mediated cell migration in an in vitro scratch assay. A- Representative images of scratch assay of HUVEC with the treatments, -ve control- without VEGF, +ve control- with VEGF (10 ng/mL), quercetin (1) $[10 \mu \mathrm{M}+10 \mathrm{ng} / \mathrm{mL}$ VEGF], quercetin (1) $[1 \mu \mathrm{M}+10 \mathrm{ng} / \mathrm{mL}$ VEGF], thioquercetin (4) $[1 \mu \mathrm{M}+10 \mathrm{ng} / \mathrm{mL} \mathrm{VEGF}]$, methoxyquercetin (2) $[10 \mu \mathrm{M}+10 \mathrm{ng} / \mathrm{mL} \mathrm{VEGF}]$, thiomethoxyquercetin (3) $[10 \mu \mathrm{M}+10 \mathrm{ng} / \mathrm{mL}$ VEGF]. The images were acquired at $10 \mathrm{X}$ maginification, size bar $50 \mu \mathrm{M}$. Dashed lines represent the margins of the initial scratch, area covered by HUVEC after $12 \mathrm{~h}$ was quatified using ImageJ software. B- Bar chart represent the quantification of the inhibitory effect of quercetin and its derivatives on VEGF stimulated migration, expressed as percentage of the scratched area covered by HUVEC after $12 \mathrm{~h}$ migration and normalized to presence/absence of VEGF (100\% and 0\% for VEGF and VEGF-free medium, respectively). The results for compound-4 at $10 \mu \mathrm{M}$ is not reported as signs of toxicity were observed for that compound at $10 \mu \mathrm{M}$ concentration. Data are expressed as mean \pm standard error of the mean (SEM), $n=3$. Statistical significance was estimated with respect to the +ve control by one-way ANOVA, followed by Bonferroni's post hoc test (ns = nonsignificant; *, p < 0.05, **, p < 0.01, ***, p < 0.001, ****, p < $0.0001)$.

Figure 12. Effects of luteolin and its derivatives on VEGF-mediated cell migration in an in vitro scratch assay. A- Representative images of scratch assay of HUVEC with the treatments, -ve control- without VEGF, +ve control- with VEGF (10 ng/mL), luteolin (10) [1 $\mu \mathrm{M}+10 \mathrm{ng} / \mathrm{mL}$ VEGF], thioluteolin (12) $[1 \mu \mathrm{M}+10 \mathrm{ng} / \mathrm{mL}$ VEGF], methoxyluteolin (9) [10 $\mu \mathrm{M}+10 \mathrm{ng} / \mathrm{mL}$ VEGF], thiomethoxyluteolin (11) [10 $\mu \mathrm{M}+10 \mathrm{ng} / \mathrm{mL}$ VEGF]. The images were acquired at $10 \mathrm{X}$ magnification, size bar $50 \mu \mathrm{M}$. Dashed lines represent the margins of the initial scratch, area covered by HUVEC after $12 \mathrm{~h}$ was quatified using ImageJ software. B-Bar chart represent the quantification of the inhibitory effect of luteolin and its derivatives on VEGF stimulated migration, expressed as percentage of the scratched area covered by HUVEC after $12 \mathrm{~h}$ migration and normalized to presence/absence of VEGF (100\% and $0 \%$ for VEGF and VEGF-free medium, respectively). The results for compounds-10 and 12 at $10 \mu \mathrm{M}$ are not reported as signs of toxicity were observed for those compounds at 10 $\mu \mathrm{M}$ concentration. Data are expressed as the mean \pm standard error of the mean $(\mathrm{SEM}), \mathrm{n}=3$. Statistical significance was estimated with respect to the +ve control by one-way ANOVA, followed by Bonferroni's post hoc test (ns = nonsignificant; $*$, p $<0.05, * * *, p<0.001, * * * *, p<0.0001$ ).

Figure 13. A-Representative Western blot images of HUVEC proteins with the treatments, -ve control- without VEGF, +ve control- with VEGF (10 ng/mL), quercetin (1) $[10 \mu \mathrm{M}+10 \mathrm{ng} / \mathrm{mL}$ VEGF], quercetin $(1)[1 \mu \mathrm{M}+$ $10 \mathrm{ng} / \mathrm{mL}$ VEGF], thioquercetin (4) $[1 \mu \mathrm{M}+10 \mathrm{ng} / \mathrm{mL}$ VEGF], methoxyquercetin (2) $[10 \mu \mathrm{M}+10 \mathrm{ng} / \mathrm{mL}$ VEGF], thiomethoxyquercetin (3) $[10 \mu \mathrm{M}+10 \mathrm{ng} / \mathrm{mL}$ VEGF $]$, luteolin (10) $[1 \mu \mathrm{M}+10 \mathrm{ng} / \mathrm{mL} \mathrm{VEGF}]$, methoxyluteolin (9) $[10 \mu \mathrm{M}+10 \mathrm{ng} / \mathrm{mL}$ VEGF], thiomethoxyluteolin (11) $[10 \mu \mathrm{M}+10 \mathrm{ng} / \mathrm{mL}$ VEGF]; actin was used as a loading control. B- Bar chart represents the quantification of the inhibitory effect of quercetin, luteolin and its derivatives on VEGF induced phosphorylation. Data are expressed as mean \pm standard error of the mean $(\mathrm{SEM}), \mathrm{n}=3$. Statistical significance was estimated vs the +ve control by one-way ANOVA, followed by Bonferroni's post hoc test (\#-significant with respect to -ve control, ns = nonsignificant; *, p < 0.05, ***, p < $0.001, * * * *, \mathrm{p}<0.0001)$. 
Figure 14. Docking modes of quercetin (1) (A), methoxy quercetin (2) (B), thiomethoxy quercetin (3) (C), thioquercetin (4) (D), luteolin (10) (E), methoxy luteolin (9) (F), thiomethoxy luteolin (11) (G), thioluteolin (12) (H) with VEGFR2.

Figure 15. Docking modes of quercetin (1) (A), methoxy quercetin (2) (B), thiomethoxy quercetin (3) (C), thioquercetin (4) (D), luteolin (10) (E), methoxy luteolin (9) (F), thiomethoxy luteolin (11) (G), thioluteolin (12) (H) with VEGF.

Figure 16. Representative DSC profiles of DPPC MLV's illustrating the effect in the presence of (A) Genistein at $10 \mu \mathrm{M}(\mathrm{G}-10 \mu \mathrm{M}), 60 \mu \mathrm{M}(\mathrm{G}-60 \mu \mathrm{M})$, and $100 \mu \mathrm{M}(\mathrm{G}-100 \mu \mathrm{M})$ in comparison with DPPC alone; (B) Quercetin and its derivatives (at 10 times the concentration at which antiangiogenic effects were observed): compound-1 at $100 \mu \mathrm{M}$, compound-2 at $100 \mu \mathrm{M}$, compound-3 at $100 \mu \mathrm{M}$ in comparison with genistein at 100 $\mu \mathrm{M}$ and DPPC alone; (C) Luteolin and its derivatives (at 10 times the concentration at which antiangiogenic effects were observed): compound-9 at $100 \mu \mathrm{M}$, compound-10 at $10 \mu \mathrm{M}$, compound-11 at $100 \mu \mathrm{M}$ in comparison with genistein at $100 \mu \mathrm{M}$ and DPPC alone.

Figure 17. Dose-dependent cytotoxicity curves of quercetin (1), thioquercetin (4), methoxy quercetin (2) and thiomethoxy quercetin (3) (A) against MCF-7 (B) against MCF-7/DX. Dose-dependent cytotoxicity curves of luteolin (10), thioluteolin (12) methoxyluteolin (9) and thiomethoxyluteolin (11) (C) against MCF-7 (D) against MCF-7/DX. Data are expressed as the mean \pm standard error of the mean $(\mathrm{SEM}), \mathrm{n}=3$.

Figure 18. General SAR of quercetin and luteolin derivatives

Table 1. Thermodynamic parameters obtained by DSC for the interaction of DPPC with compounds $1-3$ and $9-11^{\mathrm{a}}$

Table 2. $\mathrm{IC}_{50}$ values of quercetin, luteolin and their derivatives ${ }^{\mathrm{a}}$. 